\title{
The Correlation between Ion Beam/Material Interactions and Practical FlB Specimen Preparation
}

\author{
B.I. Prenitzer, ${ }^{1 \star}$ C.A. Urbanik-Shannon, ${ }^{2}$ L.A. Giannuzzi, ${ }^{2}$ S.R. Brown, ${ }^{1}$ R.B. Irwin, ${ }^{1}$ \\ T.L. Shofner, ${ }^{1}$ and F.A. Stevie ${ }^{1}$ \\ ${ }^{1}$ Agere Systems, 9333 S. John Young Parkway, Orlando, FL 32819, USA \\ ${ }^{2}$ Department of Mechanical, Materials, and Aerospace Engineering, University of Central Florida, P.O. Box 162450, \\ 4000 Central Florida Blvd., Orlando, FL 32816-2450, USA
}

\begin{abstract}
The focused ion beam (FIB) tool has been successfully used as both a stand alone analytical instrument and a means to prepare specimens for subsequent analysis by SEM, TEM, SIMS, XPS, and AUGER. In this work, special emphasis is given to TEM specimen preparation by the FIB lift-out technique. The fundamental ion/solid interactions that govern the FIB milling process are examined and discussed with respect to the preparation of electron transparent membranes. TRIM, a Monte Carlo simulation code, is used to physically model variables that influence FIB sputtering behavior. The results of such computer generated models are compared with empirical observations in a number of materials processed with an FEI 611 FIB workstation. The roles of incident ion attack angle, beam current, trench geometry, raster pattern, and target-material-dependent removal rates are considered. These interrelationships are used to explain observed phenomena and predict expected milling behaviors, thus increasing the potential for the FIB to be used more efficiently with reproducible results.
\end{abstract}

Key words: focused ion beam, redeposition TEM specimen preparation, ion solid interactions

\section{INTRODUCTION}

Transmission electron microscopy (TEM) is the preferred analytical technique for applications requiring subnano-

Received January 14, 2002; accepted May 1, 2002.

${ }^{*}$ Corresponding author. E-mail: prenitzer@agere.com

C.A. Urbanik-Shannon is now at Accurel Systems, 785 Lucerne Dr., Sunnyvale, CA 94087, USA.

R.B. Irwin is now at now at Texas Instruments, 13536 North Central Expressway, MS 947, Dalla, TX 75243.

T.L. Shofner is now at FEI Company, 7451 NE Evergreen Parkway, Hillsboro, OR 97124, USA.

F.A. Stevie is now at North Carolina State University, Analytical Instrumentation Facility, Box 7531, EGRC Room 318, 1010 Main Campus Drive, Raleigh, NC 27695, USA.

B.I. Prenitzer is now at NanoSpective, 9006 Eagle Cove Court, Orlando, FL 32825. meter scale lateral point-to-point resolution and/or detailed microstructural evaluation. Traditionally, the utility of the TEM has been somewhat encumbered by the necessary specimen preparation regimes; however, recent developments in focused ion beam technology have provided a means to rapidly prepare site-specific, high-quality TEM specimens from a number of materials (Szot et al., 1992; Hull et al., 1993, 1995; Nakajima and Sudo, 1993; Tartuani et al., 1993; Yamaguchi and Shibata, 1993; Kitano et al., 1995; Tanaka et al., 1997; Bender et al., 1998; Giannuzzi et al., 1998; Hull, 1998; Prenitzer et al., 1998; Readinger et al., 1999). Although several successful techniques for focused ion beam (FIB) TEM specimen preparation have been described in the literature, this article will refer extensively to the FIB lift-out (FIB LO) method (Kirk et al., 1989; 
Young et al., 1990; Basile et al., 1992; Sanborn and Myers, 1992; Yater and Thompson, 1992; Overwijk et al., 1993, 1998; Ishitani et al., 1994; Stevie et al., 1995, 1998a; Herlinger et al., 1996; Giannuzzi et al., 1997; Phaneuf et al., 1997; Sheng et al., 1997; Kamino et al., 1998; Young et al., 1998; Zhou and Zanoya, 1999; Langford and Petford-Long, 2001).

With the rapid maturation of FIB instruments has come an equally rapid diversification of applications. In addition to TEM specimen preparation, FIB milling techniques have also been effective in producing specimens for subsequent analysis by scanning electron microscopy (SEM), secondary ion mass spectrometry (SIMS), scanning transmission electron microscopy (STEM), AUGER electron spectroscopy (AES), and atomic force microscopy (AFM; Mackenzie et al., 1993, 1994; Young et al., 1993a; Huffman et al., 1994; Ishitani et al., 1995; Kamino et al., 1998; Prenitzer et al., 1998; Stevie et al., 1999, 2001; Vartuli et al., 1999). It should be noted that the fundamental concepts of ion-solid interactions presented in this work are equally applicable to any such potential application. Furthermore, many of the principles described are closely related to well-characterized broad ion beam phenomena. Although the similarities are numerous, the differences can be significant. The behavior of a material under the bombardment of a high-flux, moderate-energy ion beam is unique enough to deserve consideration in its own right.

\section{FIB LO Technique}

Although the FIB LO technique has been described in detail by Giannuzzi et al. (1997), it will be summarized here for completeness. The first step in the process is to deposit either a W or Pt line using the ion-beam-assisted chemical vapor deposition (CVD) capability of the FIB. The metal line serves to mark the site to be milled and protect the area of interest from inadvertent milling. Once the metal line is in place, trenches $\sim 20 \mu \mathrm{m}$ long, $\sim 5-10 \mu \mathrm{m}$ wide, and $\sim 5 \mu \mathrm{m}$ deep are milled on either side of the line using a high current density beam. The specimen thickness is then reduced by using an intermediate beam current to make alternating cuts on either side of the metal line. The specimen is then tilted to an angle of $\sim 50-60^{\circ}$, so that the bottom and a portion of one side may be cut free from the bulk. After returning to a $0^{\circ}$ tilt, the region of interest is thinned to electron transparency (i.e., $<100 \mathrm{~nm}$ ) with a low current density beam. Once the specimen is sufficiently thin, it is cut completely free from the substrate. The bulk sample is then removed from the FIB. The electron transparent membrane is extracted from the trench within the bulk sample and placed onto a carbon-coated Cu TEM grid with the aid of an optical microscope, and a three-axis hydraulic micromanipulator. At this point, the specimen is ready for TEM analysis. The entire FIB milling process takes $\sim 0.5-$ $3 \mathrm{~h}$ to complete. The actual milling time will vary with the particular instrument and specimen being milled. The overall success rate for specimens prepared by the FIB LO technique in our lab has been $>90 \%$.

FIB specimen preparation techniques have proven to be a welcome addition to a preexisting arsenal of effective TEM specimen preparation techniques (Goodhew, 1985; Williams and Carter, 1996; Anderson and Walck, 1997). Each available method is unique with respect to time and ease of preparation, site specificity, and final specimen quality. Some of the primary advantages of the FIB LO method include the ability to pinpoint a precise region of interest, the fact that specimens require little or no treatment prior to milling, and that the preparation times are generally very short. The FIB LO method is particularly well suited to the preparation of site-specific specimens from difficult starting geometries such as small fibers, powder particles, and interfaces (Yamaguchi and Shibata, 1993; Giannuzzi et al., 1998, 1999b, 1999c; Prenitzer et al., 1998; Giannuzzi and Lewinsohn, 2000; Lomness et al., 2000, 2001a, 2001b). Furthermore, a slight modification to the original FIB LO technique has enabled the successful production of specimens suitable for high-resolution TEM (HREM) imaging (Giannuzzi et al., 1999a).

The objective of the FIB LO technique is to produce high-quality TEM specimens rapidly and reproducibly. Ideally, a TEM specimen should be representative of the bulk material from which it was prepared. In practice, however, each of the available specimen preparation methods tends to be plagued by certain characteristic artifacts that diminish specimen quality. Although empirical evidence clearly shows that the quality of an FIB LO specimen is sufficient to satisfy the necessary conditions for HREM imaging of $\mathrm{Si}$ (Giannuzzi et al., 1998b), it has been observed that FIB milled features tend to exhibit some surface degradation as a direct result of the milling process (Kamino et al., 1998; Susnitsky and Johnson, 1998; Urbanik et al., 1999). The magnitude of the surface disruption is dependent on inherent material properties, the particular ion column, and the operating parameters of the FIB. Optimization of operating conditions and familiarity with inherent material properties can be used to minimize the severity of surface artifacts and 
improve success rates for novel materials. Accordingly, the interrelationships between the target material, the userselected processing parameters, and the overall process efficiency as they relate to practical aspects of specimen preparation will be addressed.

\section{Ion/Solid Interaction Theory}

\section{What Causes the Damage Layer}

Irradiation of a solid with a beam of energetic ions will generally result in some degree of microstructural disruption. For many crystalline materials, there exists a critical implantation dose, above which the lattice disruption is so extensive that the material is amorphized, while ion irradiation will cause extensive lattice defect generation in other materials. The nature of ion irradiation damage in a solid can be correlated with the unit cell size, the complexity of chemical ordering, and the width of the intermetallic phase field. Postirradiation recovery in systems with intricate chemical and structural ordering (i.e., covalently bonded compounds and ordered alloys) requires a large degree of coordinated atomic motion. Because such a transformation is kinetically unfavorable, a metastable amorphous phase generally results. Conversely, compounds that are characterized by wide phase fields, nondirectional bonding (i.e., ductile metals), and few atoms per unit cell can withstand a greater degree of chemical and structural perturbation. Such materials will generally accumulate radiation induced lattice defects but remain crystalline during ion bombardment (Brimhall et al., 1983; Nastasi et al., 1996a; Kempshall et al., 2001).

\section{Stopping Power and Range}

When a solid material is bombarded with an ion beam, a number of mechanisms operate to slow the ions and dissipate the energy. These mechanisms can be subdivided into two general categories, (1) nuclear energy losses, and (2) electronic energy losses. Nuclear energy transfer occurs in discrete steps as the result of elastic collisions where energy is imparted from the incident ion to the target atom by momentum transfer. Electronic energy losses occur in a continuous fashion in which inelastic scattering events stem from interactions between the electrons of the ion and the electrons of the target. The relative magnitude of the nuclear and electronic components is mainly dependent on the ion velocity and instantaneous charge states of the incident and target atoms, respectively. In general, nuclear stopping tends to predominate for ions traveling at velocities significantly less than the Bohr velocity $\left(\nu_{0}\right)$, where $\nu_{0}$ is the velocity of an electron in a $1 s$ orbital around a $\mathrm{H}$ nucleus, and has a value of $2.188 \times 10^{8} \mathrm{~cm} / \mathrm{s}$. At intermediate velocities, that is, $\nu \sim 0.1 \nu_{0}$ to $Z_{1}^{2 / 3} \nu_{0}$, both mechanisms are operative. In this median energy regime, nuclear stopping tends to be the primary energy transfer mechanism and the electronic stopping contribution is approximately proportional to the velocity (Ziegler et al., 1985; Nastasi et al., 1996b).

Collectively, the nuclear and electronic energy dissipation mechanisms define the total stopping power of a given ion in a particular target. The stopping power is a measure of the efficiency with which a target material slows an incident ion, and is defined as the rate of energy loss per unit path length, $d E / d x$. The total stopping power of a given ion/target combination can be approximated by equation (1):

$$
\frac{d E}{d x}=\left.\frac{d E}{d x}\right|_{n}+\left.\frac{d E}{d x}\right|_{e}
$$

The main parameters that govern energy loss rates are the kinetic energy of the incident ion $\left(E_{0}\right)$, the atomic masses $\left(M_{1}\right.$ and $\left.M_{2}\right)$, and the atomic numbers $\left(Z_{1}\right.$ and $\left.Z_{2}\right)$ of the ion and the target atoms, respectively.

Closely related to the stopping power of a given ion/ atom pair, is the range $(R) . R$, as described by equation (2),

$$
R=\int_{E_{o}}^{0} \frac{1}{d E / d x} d E
$$

is defined as the integrated distance that an ion travels while moving in a solid. It can be seen that the distance an ion will travel in a solid medium is inversely related to its stopping power as described above.

$R$ describes the penetration behavior of a single ion. However, ion beam processes require the collective effect of large numbers of ions. Therefore, the longitudinal projected range $\left(R_{p}\right)$ is a more appropriate parameter for describing ion implant depths. $R_{p}$ is the depth at which the highest concentration of implanted ions will be found. For FIB applications, stopping of an energetic particle is a random process, and the range distribution of a sufficiently large population of ions is statistical in nature. In many cases, a Gaussian probability function can be used to represent this distribution. The mean is interpreted as the average projected range, $\overline{R_{p}}$, and the standard deviation as the projected 
range straggling $\left(\Delta R_{p}\right)$. For a more comprehensive treatment of range concepts see Gibbons et al. (1975), Zeigler et al. (1985), Nastasi et al. (1996c), and Prenitzer (1999).

The study of ion-solid interactions is, in essence, the study of the many avenues by which the kinetic energy of an incident ion may be transformed and redistributed in a target material. It is precisely these energy transfer mechanisms that cause the phenomena that are characteristic of a material undergoing ion bombardment, for example, sputtering, phonon production, the emission of $\mathrm{X}$ rays, Auger electrons, and secondary electrons, as well as the generation of lattice defects. By making critical evaluations of such physically observable phenomena, the underlying ion-solid interactions may be discerned. Such fundamental information can then be applied to help predict milling behavior as well as irradiation-induced damage. For example, a $25-\mathrm{keV}$ $\mathrm{Ga}^{+}$ion travels with an approximate velocity of $8 \times 10^{7} \mathrm{~cm} / \mathrm{s}$. This is an energy regime where nuclear stopping is dominant. Thus, nuclear scattering events act to slow the incident ions, and ultimately determine the final spatial distribution of the implanted ions in the solid. Depending on the energy of the collision, an elastic scattering event can produce ejected neutrals or ions, vacancies, self interstitials, ion interstitials, or substitutional occupation of the lattice site by an ion. The excess energy from any collision with insufficient energy to cause a displacement will be released in the form of phonons creating a localized momentary temperature elevation. Thermal spikes may contribute to both the formation as well as the annealing of ion irradiationinduced artifacts. Thus, it can be seen how understanding ion-solid encounters is essential to achieving optimal results in any ion beam instrument.

Computer-aided calculations of ion-solid interactions can greatly simplify the process of estimating sputtering rates, the intensity of ion-induced secondary electron emission, and the magnitude of the milling-induced damage layer for any given set of parameters (e.g., incident ion, target material, ion energy, etc.). Multiple methodologies have been applied in the area of computer modeling (Biersack and Haggmark, 1980; Guinan and Kinney, 1982; Adesida and Karapiperis, 1982; Garrison et al., 1994; Sanders et al., 1994; Rosencrance et al., 1995); however, as long as the criteria illustrated below are met, readily available Monte Carlo methods may be used. When a target atom receives enough energy to knock it from its lattice position, it can contribute to the collision cascade, that is, the moving sea of particles within a solid under ion bombardment. The nature of the collision cascade depends on the ratio $M_{1}: M_{2}$, and the incident ion energy, $\left(E_{0}\right)$. For a typical FIB application using a $25-50-\mathrm{keV} \mathrm{Ga}^{+}$ion beam, $E_{0}$ is moderate, and $M_{1} \approx M_{2}$; thus the type of cascade produced falls into the linear cascade regime. The linear cascade approximation is valid when the number of moving atoms is small with respect to the total number of atoms contained within the collision volume. Under these conditions, elastic energy losses can be assumed to be the result of a series of uncorrelated binary collisions. The random statistical nature of linear collision cascade dynamics allows FIB-induced collision phenomena to be modeled with Monte Carlo computer simulation methods.

\section{Monte Carlo Models Using TRIM}

Transport of Ions in Matter (TRIM) is a subroutine of a group of programs called Stopping and Range of Ions in Matter (SRIM) created by Zeigler and coworkers (Biersack and Haggmark, 1980; Zeigler et al., 1985). TRIM can be used to model final three-dimensional spatial distributions of ions in either simple or complex target materials. SRIM can be used to calculate range data in two basic ways. Modeling can be done by Monte Carlo simulation with TRIM or analytically using STOP, which is also a subroutine of SRIM. STOP uses the Projected Range Algorithm (PRAL) code to generate range data with a greater degree of accuracy than the $\sim 20 \%$ attainable by calculation with Lindhard, Scharff, and Schiott (LSS) methods (Lindhard, 1953; Lindhard et al., 1954; Gibbons et al., 1975). TRIM can also be used to generate kinetic data associated with the slowing of incident ions in a solid, that is, target damage, sputtering, ionization, and phonon production.

There are several Monte Carlo simulation codes that can be used to model ion-solid interactions. One of the primary distinctions lies in the assumptions with respect to the crystalline state of the target material. TRIM treats all targets as amorphous. Thus, any contribution due to crystallographically dependent phenomena such as channeling is discarded from TRIM simulations. Marlowe (Robinson and Torrens, 1974; Moore and Srinivasan, 1988) models crystalline structures for a standard and much more limited set of target materials. SUPREM-3 (Crandle et al., 1989) can be used to model $\mathrm{Si}$ where the target starts as crystalline and gradually becomes amorphous as damage accumulates; that is, the effects of channeling are weighted less as amorphization progresses.

With the strengths and the limitations of the SRIM package in mind, the code has been used to model variables 
that govern the FIB milling process. This work compares the computer-generated models with empirical observations in order to gain insight into the ion-solid interactions that drive FIB milling processes. The applications for this information are numerous; however, the specific focus of this article is to determine the appropriate milling parameters to successfully and reproducibly produce electron transparent specimens.

\section{Materials And Methods}

\section{Computer Modeling Experiments}

\section{Sputtering Yield Models}

TRIM was used to model sputtering yields as a function of incident angle and target material $(Y(Z, \theta))$ of selected materials, $Z=3-84$. To generate the full complement of corresponding kinetic data, the simulations were performed as detailed calculations with full damage cascades. The associated parameters were selected as $25-\mathrm{keV} \mathrm{Ga}^{+}$impinging on the target at three discrete angles (i.e., $\theta=0^{\circ}, 80^{\circ}$, and $89^{\circ}$ from the surface normal). The computer-simulated sputtering data for elements, $Z=13-30$ irradiated at $\theta=0^{\circ}$, $80^{\circ}$, and $89^{\circ}$ was used to generate plots illustrating the $Z$ dependence of sputtering yield $(Y=Y(Z, \theta))$ at each of the three fixed $\theta$ values. The $Y(Z, \theta)$ data was also correlated with $T_{m}(Z)$ for elements $13-30$. The TRIM program was further used to explicitly model the variation in $Y(Z, \theta)$ for a given $Z$ as $\theta$ is varied. MC calculations for $Y(Z, \theta)$ of $Z=$ $14,13,29,30$ (i.e., Si, $\mathrm{Al}, \mathrm{Cu}$, and $\mathrm{Zn}$ ) were made at $10^{\circ}$ intervals in the angular range $\theta=0-80^{\circ}$, and every $2^{\circ}$ for $\theta=81-89^{\circ}$. The modeled $Y(Z, \theta)$ data for elements $\mathrm{Si}, \mathrm{Al}$, $\mathrm{Cu}$, and $\mathrm{Zn}$ was plotted as a function of $\theta$.

\section{Stopping Power and Range Models}

In addition to sputtering data, TRIM was used to model stopping powers and ion range distributions for $25-\mathrm{keV}$ $\mathrm{Ga}^{+}$into target elements $Z=3-84$. The total stopping power of $25-\mathrm{keV} \mathrm{Ga}^{+}$in target elements $Z=1-92$ was modeled with the PRAL algorithm, and plots of the computer-predicted stopping data with respect to target material have been superimposed on plots of $\rho_{m}(Z)$ and $T_{m}(Z)$. The graphs highlight the analogous materialdependent periodic behavior exhibited by different physical properties.

\section{Milling Experiments}

Implantation Damage: TEM of Trench Sidewall in (100) Si

To substantiate the computer models, complementary milling experiments were performed. Ion range predictions were compared with observed $\mathrm{Ga}^{+}$ion irradiation-induced sidewall damage. The potential to generate lattice defects during FIB milling was investigated by using the FEI 611 FIB to mill a $10 \mu \mathrm{m} \times 5 \mu \mathrm{m}$ trench in (100) Si at normal incidence with a beam current of $1000 \mathrm{pA}$. The sample was then removed from the FIB and an Emitech K675 was used to sputter coat a layer of $\mathrm{Cr}$ to protect the surface integrity of the trench sidewalls and bottom. The Si wafer was subsequently returned to the FIB where it was back-filled with $\mathrm{W}$, and a cross-sectional TEM specimen of the trench sidewall was prepared according to the FIB LO procedure. TEM analysis of the sidewall region was performed with the Phillips EM 430 to evaluate the nature and magnitude of the damage imparted during FIB milling of the original trench.

\section{Redeposition-Related Artifacts}

In addition to considering lattice defect generation, a systematic evaluation of the factors that influence redepositionrelated surface artifacts was performed. The effects of variations in raster pattern, beam current, and material properties were evaluated in one or all of five possible target materials. The materials sampled were: (1) single crystal (100) Si used in semiconductor manufacturing, (2) single crystal (100) Cu grown from seed, (3) single crystal (110) $\mathrm{Cu}$ grown from seed-Cu orientations determined by back reflection Laue X-ray diffraction methods, (4) 99.999\% polycrystalline $\mathrm{Al}$ commercially produced, and (5) polycrystalline $\mathrm{Zn}$ from the center of a current Lincoln U.S. cent. The $\mathrm{Cu}, \mathrm{Al}$, and $\mathrm{Zn}$ were metallographically prepared prior to the initiation of FIB milling. SiC papers of decreasing grit size $(600,800$, and 1200) were used for rapid material removal. The subsequent polishing steps were performed with diamond polishing suspensions of $6 \mu \mathrm{m}$ followed by $1 \mu \mathrm{m}, 0.1 \mu \mathrm{m}$, and $0.05 \mu \mathrm{m}$, all on felt polishing cloths and lubricated with deionized water. After polishing, the samples were ultrasonically cleaned with deionized water, subsequently rinsed with deionized water, room temperature acetone, and finally hot acetone.

A conductive $\mathrm{C}$ coating was applied to the samples using the Hitachi HUS-5GB high-vacuum evaporator. Un- 
less otherwise stated, all of the milling was performed with an FEI $611 \mathrm{FIB}$ at a magnification of $5000 \times$, with dwell time fixed at $0.1 \mu \mathrm{s}$, and overlap at $50 \%$. After the initial trenches were cut, the samples were removed from the FIB and sputter coated with $\mathrm{Cr}$ in an Emitech model K675. The coating parameters were set to oxidizing target, $450 \mathrm{~mA}$ for a duration of 3:00 minutes. After $\mathrm{Cr}$ coating, the samples were placed back into the FIB so that the trenches could be cross-sectioned to facilitate SEM analysis with the Hitachi H4100.

The milling experiments were designed so that all but one of the milling parameters were either held constant or allowed to vary in a controlled fashion. This allowed the effects of a single independent variable to be isolated and observed. The details of the individual milling experiments are listed below as categorized according to the independent variable:

- Variations with raster pattern;

- Variations with beam current;

- Variations with material properties.

\section{Raster pattern}

By design, the beam size of an FIB is on the order of nanometers in diameter; therefore, in order to mill a feature that is several microns square in dimension, the fine probe must be scanned or rastered over the entire area. The raster pattern is an assemblage of discrete steps taken by the beam as it moves within the defined raster field. The rate of advance of the beam in the FEI FIBs is controlled by the length of time the beam spends in a single location (the dwell time) and the size of the steps it takes between adjacent locations (the overlap). The number of steps required to create a feature of a given size will increase as the percent overlap is increased. The dwell time determines the amount of material that will be removed from a single site per step. The directional sequence of the individual steps defines the path that the beam follows. The software associated with the FEI instruments allow the path, dwell, and overlap of the beam to be defined and stored collectively as a raster pattern algorithm. Another feature of the FEI software is the ability to calculate and store material files, which are based on the sputtering yield for a particular material. The automated FEI software fixes the total pattern time according to the user-selected raster pattern, trench dimensions, and material file.
Table 1. The milling parameters used to mill the series of raster patterns in (100) Si

\begin{tabular}{lllr}
\hline FEI algorithm & $\begin{array}{l}\text { Beam current } \\
(\mathrm{pA})\end{array}$ & Dose & $\begin{array}{r}\text { Time } \\
(\mathrm{min}: \mathrm{s})\end{array}$ \\
\hline SST & 1000 & $4.9 \times 10^{12}$ & $13: 38$ \\
CUC & 1000 & $8.6 \times 10^{12}$ & $23: 06$ \\
\hline
\end{tabular}

The effect that the raster pattern exerts on specimen surface quality was evaluated by milling into (100) Si using standard FEI raster patterns, the stair-step trench (SST) and the clean up cut (CUC). Both of these raster patterns are described in detail in the Results section. This experiment was intended to simulate the initial milling steps used in the FIB LO method; therefore a 500-pA beam current was used to deposit a $14 \mu \mathrm{m} \times 0.4 \mu \mathrm{m} \times 4 \mu \mathrm{m} \mathrm{W}$ line prior to milling the trenches. The trenches were milled with a 1000 -pA beam current and an overlap of $50 \%$. The total delivered $\mathrm{Ga}^{+}$ion dose was subsequently calculated from the displayed pattern time and beam current as shown in Table 1 . The trench dimensions were nominally selected to be $14 \mu \mathrm{m} \times 5 \mu \mathrm{m} \times 3 \mu \mathrm{m}$ and the "Si.mtr" file was selected.

\section{Variable beam current}

Varying the beam current alters the probe diameter and the ion flux delivered to the target. As the beam current is increased, the number of incident ions available to interact with the target increases, resulting in an increased removal rate, $Y_{t}$. The beam current is increased in the FEI 611 by increasing the aperture size. Table 2 shows the relationship between aperture size, beam current, probe size, and $\mathrm{Ga}^{+}$ ion flux in the FEI 611.

Two sets of experiments investigating the effect that beam current exerts on specimen surface quality were performed. All milling was performed using the standard Si.mtr file as included in the FEI software database. In the initial experiment, three $10 \mu \mathrm{m} \times 2 \mu \mathrm{m} \times 8 \mu \mathrm{m}$ trenches were milled in (100) Si by using beam currents of 500, 1000, and 2000 pA. The exaggerated $8 \mu \mathrm{m}$ depth dimension was selected so that the aspect ratio would be limited as a dynamic result of redeposition in the formation of the V shape. 
Table 2. Beam parameters calculated for $25-\mathrm{keV} \mathrm{Ga}^{+}$ions at a $25-\mathrm{mm}$ working distance, and $10-\mathrm{kV}$ extraction voltage in the FEI 611

\begin{tabular}{lcllr}
\hline $\begin{array}{l}\text { Aperture } \\
(\mathrm{mrad})\end{array}$ & $\begin{array}{l}\text { Beam } \\
\text { current } \\
(\mathrm{pA})\end{array}$ & $\begin{array}{l}\text { Beam } \\
\text { diameter } \\
(\mu \mathrm{m})\end{array}$ & $\begin{array}{l}\text { Current } \\
\text { density } \\
\left(\mathrm{A} / \mathrm{cm}^{2}\right)\end{array}$ & $\begin{array}{r}\text { Ion flux } \\
\left(\mathrm{Ga}^{+} / \mathrm{s} \cdot \mathrm{cm}^{2}\right)\end{array}$ \\
\hline 1.0 & 64 & 0.064 & 2.0 & $1.2 \times 10^{19}$ \\
2.0 & 250 & 0.11 & 2.6 & $1.6 \times 10^{19}$ \\
2.8 & 500 & 0.13 & 3.8 & $2.4 \times 10^{19}$ \\
4.0 & 1000 & 0.15 & 5.7 & $3.6 \times 10^{19}$ \\
5.6 & 2000 & 0.18 & 7.9 & $4.9 \times 10^{19}$ \\
\hline
\end{tabular}

Table 3. The milling parameters used to mill the series of $5 \times 10 \mu \mathrm{m}$ trenches in (110) $\mathrm{Cu}$ and (100) Si

\begin{tabular}{llr}
\hline $\begin{array}{l}\text { Beam current } \\
(\mathrm{pA})\end{array}$ & Dose & $\begin{array}{r}\text { Time } \\
(\mathrm{min}: \mathrm{s})\end{array}$ \\
\hline 2000 & $5.7 \times 10^{12}$ & $7: 30$ \\
1000 & $5.7 \times 10^{12}$ & $15: 00$ \\
500 & $5.7 \times 10^{12}$ & $30: 00$
\end{tabular}

In the second experiment, a known and constant dose of $5.7 \times 10^{12} \mathrm{Ga}^{+}$ions was used to mill three $10 \mu \mathrm{m} \times$ $5 \mu \mathrm{m}$ trenches in (100) $\mathrm{Si}$ and in (110) $\mathrm{Cu}$ at three beam currents. The ion dose was controlled by selecting the milling times to correspond to the beam currents of 500, 1000 , and $2000 \mathrm{pA}$, respectively. The milling parameters are shown in Table 3.

\section{Sputtering yield}

Sputtering yield is shown to be a major contributing factor to the development of redeposition-related surface artifacts during FIB milling. The material dependence of sputtering yield was evaluated by milling a series of $10 \mu \mathrm{m} \times$ $5 \mu \mathrm{m}$ trenches in $\mathrm{Si}, \mathrm{Al}, \mathrm{Cu}$, and $\mathrm{Zn}$ at normal incidence. $\mathrm{A}$ constant dose of $7.5 \times 10^{12} \mathrm{Ga}^{+}$ions was delivered over each $50-\mu \mathrm{m}$ area corresponding to a single trench in each material by milling with a 1000-pA beam current for $1200 \mathrm{~s}$.

Collectively, the results of the experimental work provide insight into the FIB milling process as the calculated theoretical predictions, computer models, and empirical observations are compared.

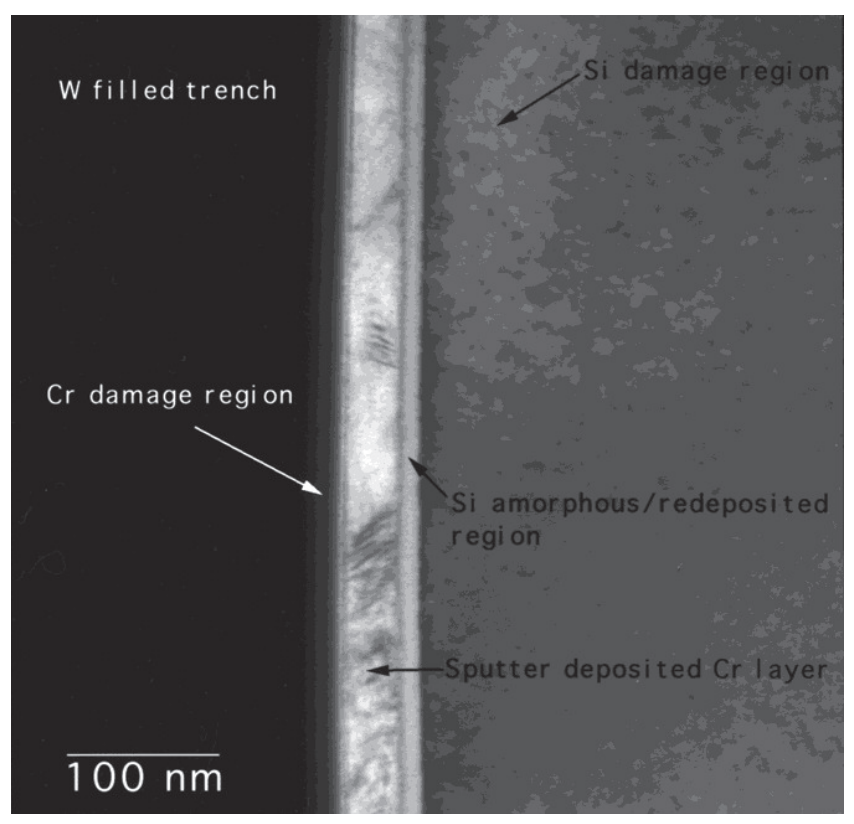

Figure 1. A cross section TEM image of a trench sidewall milled into (100) Si using a 1000-pA beam current in the FEI 611 FIB. The micrograph shows the damage that can be incurred as a result of FIB milling.

\section{Results And Discussion}

\section{FIB Milling-Induced Surface Artifacts}

\section{$\mathrm{Ga}^{+}$Implantation}

Understanding, exploiting, and to an extent controlling ion-solid interactions have been central to the development of current analytical and processing technologies involving ion beams. Of specific interest is how site-specific material removal or site-specific CVD can be accomplished by bombarding a target with a finely focused ion beam. The role of FIB instruments as such a tool is rapidly becoming well established. The FIB has been successfully used as a standalone analytical instrument (Chabala et al., 1988; Campbell and Soden, 1998; Phaneuf et al., 1998; Stevie et al., 1998b) as well as a tool for the preparation of specimens for subsequent analysis by other instruments (Stevie et al., 1999). In spite of the excellent results observed, FIB processes do lead to a final distribution of implanted $\mathrm{Ga}^{+}$ions and associated lattice defects within the active collision volume of the target material. Thus, applications of FIB instruments (e.g., TEM specimen preparation) are not accomplished without some degree of surface degradation, as is shown in Figure 1. 
Figure 1 is a cross-sectional bright field (BF) TEM image of an FIB trench sidewall. The TEM specimen was prepared by the FIB LO technique. The original trench was milled in (100) Si with a $1000-\mathrm{pA} \mathrm{Ga}^{+}$ion beam using an FEI 611 workstation operating at $25 \mathrm{kV}$. Figure 1 clearly shows several distinct layers. Starting from the left, the dark region is the $\mathrm{W}$. The next layer is believed to be surface damage to the $\mathrm{Cr}$ layer created during the initial moments of the ion-beam-assisted CVD process. CVD occurs as the ion beam acts on a continuously refreshed monolayer of molecules adsorbed on the target surface. Each pass of the beam decomposes the adsorbed molecular complexes into a thin layer of deposited material and a gas that is removed by the vacuum system. During the early stages of the CVD process, the deposited layer is too thin to prevent the incident ions from penetrating into the target material. Thus, the ion-beam-assisted CVD process is characterized by a small amount of target material removal (surface damage) that precedes deposition (Kempshall et al., 2002). To the right of the Cr damage layer is the $\sim 40$-nm-thick protective Cr layer. Next there is a sharp interface and what is believed to be the Si amorphous region. Experimental evidence strongly indicates that redeposited material is contained within the amorphous layer. The single crystal bulk Si extends beyond the clearly delimited amorphous region. The mottled appearance of the $\mathrm{Si}$ region is believed to correspond to the $\mathrm{Si}$ damage region. In this region, the $\mathrm{Ga}^{+}$ ion implant dose was not sufficient to cause amorphization, but appears to have resulted in the formation of lattice defects that extend for several hundred nanometers. The image in Figure 1 illustrates how surface artifacts (i.e., defect generation) with the upper limit of amorphization in Si can occur as a result of ion implantation. As a note, because the sample is a cross section of a cross section, any damage that would be imparted to the specimen by using the lift-out technique is on the specimen face (i.e., perpendicular to the original damage layer). Thus, the micrograph shown in Figure 1 is representative of the sidewall damage incurred while milling the original trench.

\section{Redeposition}

In addition to lattice disruption caused by impinging $\mathrm{Ga}^{+}$ ions, the redeposition of sputtered material is a second potential contributor to surface degradation in FIB-milled specimens. Redeposition tends to be pervasive in FIB applications due to localized high sputtering yields and unique milling geometries. The FIB is most often used to create features of high aspect ratio, for example, deep narrow trenches. Sputtered material tends to redeposit on surfaces that are in close proximity to the active milling site. Thus, FIB-milled trenches often develop undesirable topographical features and sloped sidewalls (Prenitzer et al., 1998). Controlling or at least predicting the manner in which redeposition of sputtered material will occur can be a significant factor in the successful and rapid production of TEM and SEM specimens by FIB techniques.

Redeposition is a function of a number of physical variables, some of which include:

- The kinetic energy of the atoms leaving the surface;

- The sticking coefficient of the target material;

- The geometry of the feature being milled;

- The raster pattern of the incident ion beam;

- The rate at which atoms are sputtered from the target material.

\section{Kinetic energy and sticking coefficient}

When an atom leaves a target material as a sputtered particle, it is ejected with a finite kinetic energy. A sputtered particle can, therefore, be considered to be a projectile capable of producing secondary interactions with any region of the target that lies in its trajectory. The sticking coefficient is a material-dependent property. It is a statistical measure of the affinity of an atom or molecule to adhere to a surface. A value of unity corresponds to $100 \%$ probability for sticking. Thus, the likelihood that a sputtered entity will be redeposited on a surface that it strikes may be estimated based on the energy of impact and the sticking coefficient of the material.

\section{Geometry of the feature being milled}

The direction in which atoms are ejected from a surface during sputtering follows a cosine distribution, with the most probable direction being normal to the surface from which it was ejected. Figure 2 schematically illustrates how the sidewalls of an FIB-milled trench are surfaces in likely positions for collision with sputtered material. It should be noted that when preparing a TEM specimen by the FIB LO method, the region of interest is embedded in the trench sidewall. Thus, the geometry of the feature being milled affects both the milling properties and the final characteristics of electron microscopy specimens prepared by FIB methods. 


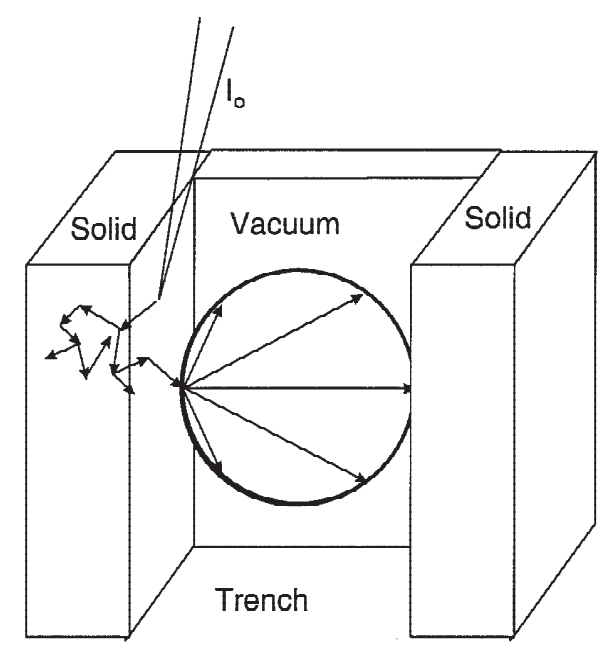

Figure 2. The ejection direction for atoms sputtered from a surface follows a cosine distribution.

\section{Raster pattern}

Consideration of the raster pattern adds two dynamic variables to the static effect of trench geometry. Both the path taken by the beam and the rate of advance strongly influence the spatial characteristics of the milled feature. The SST is an example of a raster pattern that is stored as a preprogrammed algorithm in the FEI software (Yamaguchi et al., 1985). The SST is produced as the beam is rastered repeatedly and continuously over an area selected by the user. The SST is characterized by depth gradations, with the deepest portion of the trench being adjacent to the region of interest. A greater volume of material is removed near the region of interest because the SST algorithm directs the rastered beam to spend a larger percentage of the total pattern milling time acting upon that area. Another FEI preprogrammed algorithm, the CUC, has produced promising results in Si materials. Like the SST, the deepest portion of a CUC trench is adjacent to the region of interest; however, the mechanisms of formation are unique. The depth variation in the CUC results from the increased sputtering rate caused by edge effects as opposed to the greater amount of time that the beam spends near the region of interest in the case of the SST. When the CUC algorithm is selected, the beam mills a sequence of lines parallel to the region of interest. The first line is milled farthest from the region of interest, and the beam advances one step toward the region of interest after the completion of each line. In contrast to the SST, the final pass of the beam in a CUC is along a line parallel and adjacent to the
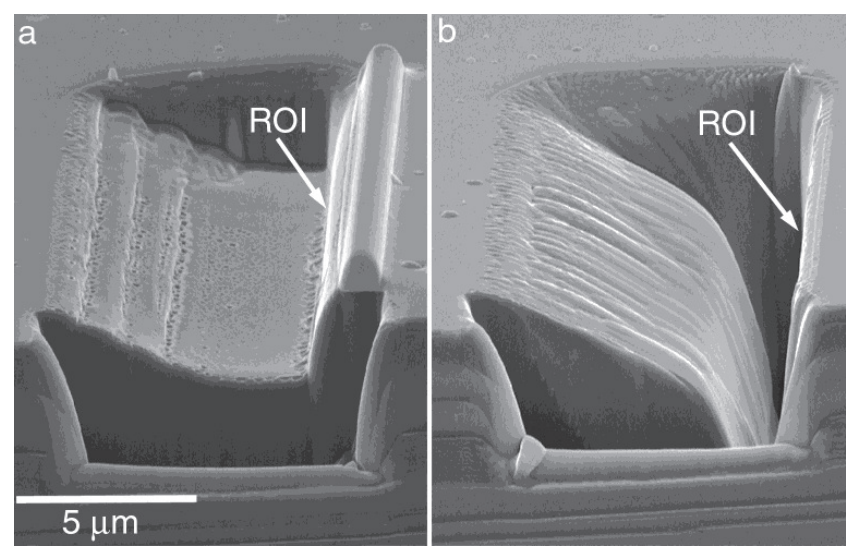

Figure 3. The cross section SEM images observed at a $70^{\circ}$ tilt show the differences in the trenches produced with the FEI stair step trench and the clean up cut algorithms. a: Stair step trench. b: Clean up cut. Both trenches were milled in (100) Si using a 1000 pA beam current

region of interest. This final milling step in the CUC significantly reduces the potential for redeposited material to remain on the region of interest. Thus, the CUC algorithm has been observed to produce a "cleaner" specimen surface than is observed in the SST. Figure 3a,b shows SEM images of a SST and a CUC, respectively. Both trenches were milled in (100) Si with a 1000-pA beam current, 50\% overlap, 1 - $\mu$ s dwell, and are nominally $14 \mu \mathrm{m} \times 5 \mu \mathrm{m} \times 3 \mu \mathrm{m}$ in dimension. The maximum depth of the SST in Figure 3a is considerably less than that observed for the CUC in Figure $3 \mathrm{~b}$. In addition, the right-hand side of each trench is the sidewall that contains the region of interest in a specimen being prepared by the FIB LO method. This sidewall is less sloped in the trench produced with the CUC. The images in Figure 3 clearly show that trenches produced with the CUC are cleaner and more vertical, thus reducing the need for some of the intermediate milling steps that are required with the SST. The elimination of steps saves time and reduces the exposure of the region of interest to the ion beam. Thus, in many applications, favorable results are obtained with the CUC.

\section{Sputtering rate}

The sputtering yield $(Y)$ can be interpreted as the average number of target atoms ejected from the sample per incident $\mathrm{Ga}^{+}$ion. It is important to make a distinction between sputtering rate $\left(Y_{t}\right)$ and $Y$, the sputtering yield. $Y$ is an event-dependent measure of the material removal. $Y_{t}$ is 
the number of atoms being sputtered from the target per unit time. Therefore, $Y_{t}$ is the actual time-dependent, kinetic material removal parameter. For FIB applications, a reasonable estimate of $Y_{t}$ can be made by multiplying $Y$ by the beam current (i.e., the rate of delivery of ions to the target surface).

The rate at which atoms are ejected from the target has a profound effect on the observed degree of redeposition. In the ideal case, where no redeposition occurs, the number of sputtered atoms ejected from the target per unit time $\left(Y_{t}\right)$ equals the number of atoms introduced into the vacuum chamber per unit time. However, when milling an actual trench, not all atoms escape into the vacuum. A significant portion of the sputtered material is retained within the trench via redeposition. Ultimately, a state of dynamic equilibrium between the rate of material removal and the rate of redeposition will be attained. The rate of redeposition is ultimately a function of the dynamic equilibrium between $Y_{t}$ and the efficiency with which the sputtered atoms can escape from the confines of the trench. Smaller trench openings tend to restrict the effusion of sputtered atoms. Thus, the severity of redeposition is a function of both $Y_{t}$ and the trench proportions. The mechanism that has been proposed to explain the "Classic V Shape" (Yamaguchi et al., 1985; FEI Focused Ion Beam Application Note, 1993; Walker, 1993; Young et al., 1993b; Ishitani et al., 1994; Bender et al., 1998) can be instructive in illustrating how the observed limits on aspect ratios attainable by FIB milling are caused by redeposition. As a trench deepens, the confining geometry restricts the escape of sputtered material. The result is that the rate of redeposition increases with trench depth until ultimately an equilibrium state is reached. This equilibrium depth limits the aspect ratio since the rate of redeposition is equal to the rate of sputtering. Thus for a given trench perimeter, factors that enhance the kinetics of material removal will tend to increase problems associated with redeposition. Therefore, it is prudent to consider the variables that influence $Y_{t}$ in order to develop a generalized and efficient methodology for FIB electron microscopy specimen preparation. Some of the primary factors that influence $Y_{t}$ are:

- Beam current $\left(I_{0}\right)$;

- Target material properties;

- Incident ion attack angle.

Beam current. The effect of beam current on FIB milling times, development of undesired surface topography, and trench geometry in single crystal $\mathrm{Cu}$ and $\mathrm{Si}$ has been
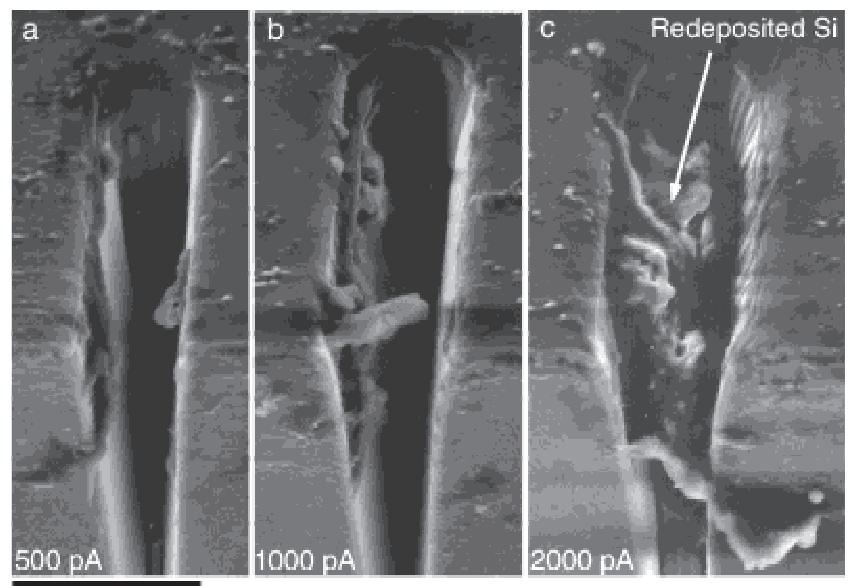

$5.0 \mu \mathrm{m}$

Figure 4. Cross section SEM images of FIB trenches milled into the edge of a (100) Si wafer at varying beam currents [i.e., $500 \mathrm{pA}$ (a), $1000 \mathrm{pA}$ (b), and $2000 \mathrm{pA}$ (c)]. When the trenches are observed at the $45^{\circ}$ tilt as shown, the milling characteristics associated with each beam current can be assessed.

investigated. Figure 4 shows SEM images of three trenches in $\mathrm{Si}$ observed at a $45^{\circ}$ tilt. The trenches were milled with the FEI 611 in single crystal (100) Si at normal incidence. All other milling parameters were held constant while the beam current was varied for each trench. The trenches shown in Figure 4a-c were milled using a 500-pA, a 1000pA, and a 2000-pA beam current, respectively. The SEM micrographs in Figure $4 \mathrm{a}-\mathrm{c}$ show the characteristic and expected variation in trench depth, shape, and degree of redeposition as a function of beam current. It can be seen from Figure $4 b, c$ that as the beam current increases, (1) the amount of redeposited material increases, (2) the sidewalls exhibit an increasing curvature with an overall increase in slope angle, and (3) the trench perimeter broadens.

Figure 5 shows SEM images of a series of FIB trenches that were made by delivering a predetermined dose of $\sim 5.6 \times 10^{12} \mathrm{Ga}^{+}$ions over an area of $5 \mu \mathrm{m} \times 10 \mu \mathrm{m}$. Two materials are shown, (110) $\mathrm{Cu}$ and (100) Si. Although the total delivered dose was constant, the rate of delivery was varied by increasing the beam current. The effect of increasing beam current can be seen within each group. Examination of Figure $5 \mathrm{~d}-\mathrm{f}$ reveals an increase in the amount of redeposited material that is retained within the Si trenches with increasing beam current. The trench milled at $500 \mathrm{pA}$, as shown in Figure 5d, is characterized by near vertical sidewalls and sharply defined edges and corners. This can be contrasted with the edges and corners of the trench sidewalls milled at progressively higher beam currents. The 


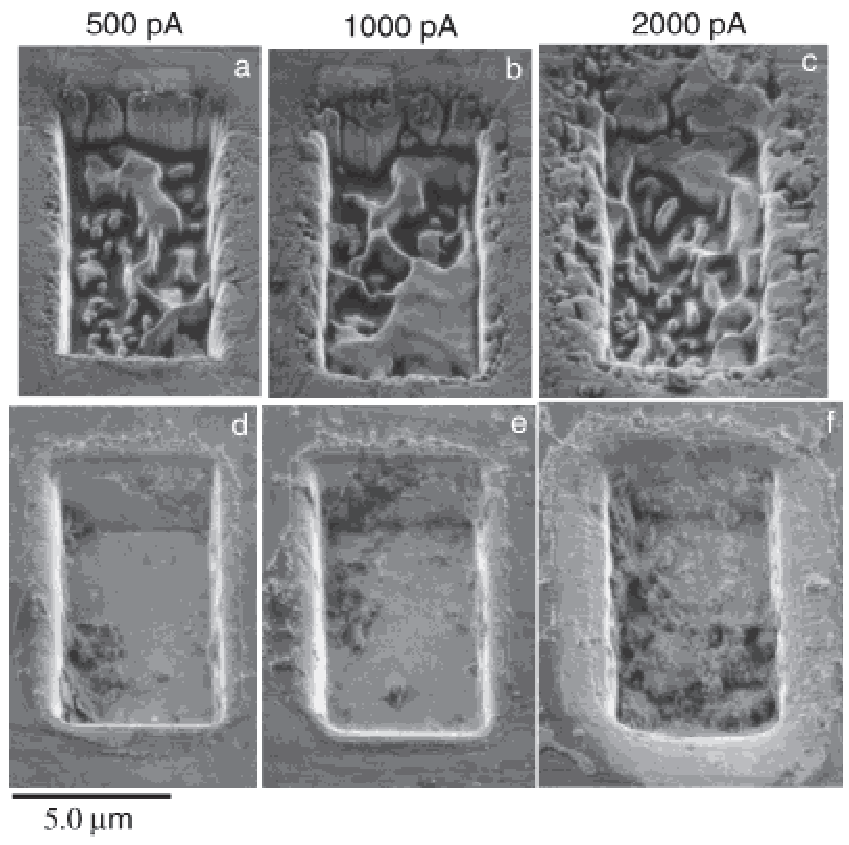

Figure 5. SEM images of the six $5 \mu \mathrm{m} \times 10 \mu \mathrm{m} \times \sim 3 \mu \mathrm{m}$ trenches milled in (110) $\mathrm{Cu}(\mathbf{a}-\mathbf{c})$ and (100) Si (d-f) using an FEI 611 FIB instrument. The milling was performed by using various beam currents [i.e., 500 pA (a,d), 1000 pA (b,e), and 2000 pA (c,f)] to apply a constant dose of $5.65 \times 10^{12} \mathrm{Ga}^{+}$ions to each trench.

1000-pA trench, shown in Figure 5e, exhibits an increased loss in definition. In the extreme case of the 2000-pA trench, shown in Figure 5f, the edges and corners are virtually obscured. Additionally, there is a large amount of redeposited material both within the confines of the trench and on the exterior surface bordering the 2000-pA trench. It should be noted that the nonuniform perimeter surrounding the trench may not be entirely due to redeposition. As shown in Table 2, higher beam currents are selected by increasing aperture size. Thus, the probe tends to lose definition at higher beam currents (Prenitzer, 1999). By comparing the characteristics of trenches produced at various beam currents, it is clear that to reduce the severity of redeposition related artifacts, milling should be performed with the lowest beam current that is tolerable, time permitting.

Comparing the milling behavior of the two materials, it can be seen that while Si tends to mill fairly uniformly, the $\mathrm{Cu}$ trenches shown in Figure 5a-c exhibit substantial formation of milling-induced topography which is pervasive at all beam currents. The same type of nonuniform milling has been observed both in polycrystalline $\mathrm{Cu}$ and in single crystal $\mathrm{Cu}$ milled in other crystallographic orientations. The nucleation of such irregularities is the subject of current investigation.

In summary, feature geometry and target material properties influence both the milling properties and the final characteristics of electron microscopy specimens prepared by FIB methods. Although it is not possible to modify the inherent milling characteristics of a specific material, knowledge of ion beam/material interactions may assist in successfully preparing electron microscopy specimens from difficult materials. For example, a desired sputtering rate can be maintained in a material with a characteristically high sputtering yield by milling at a reduced beam current.

Material dependence. Different materials have been observed to behave uniquely under the influence of the ion beam (i.e., scattering behavior resulting from ion-atom collisions is strongly material dependent). This material dependence corresponds to other periodic trends in physical phenomena exhibited by condensed phase materials (i.e., melting temperature, density, hardness, elastic modulus, thermal expansion behavior, and strength). It is the interatomic potential (i.e., the forces that bind the individual atoms together) that governs the physical characteristics of a given material. The interatomic potential function is a model of how the potential energy of a two-particle system varies as a function of their separation distance. As an example, the average kinetic energy of a target atom at room temperature (i.e., $T=298.15 \mathrm{~K}$ ) is $\sim 0.0026 \mathrm{eV}$. This is seven orders of magnitude less than that of an ion accelerated down a typical FIB column. When atoms/ions interact at velocities that exceed that of thermal motion, the distance of closest approach (the collision parameter) is considerably less than the equilibrium separation distance of the interacting species. Based on a value for the collision parameter, the material-specific interatomic potential can be used to predict the most probable outcome of a close encounter between an energetic ion and a solid. Energy loss of moderate to low energy ions (i.e., $25-50 \mathrm{keV}$ ) to target atoms can be modeled as screened Coulomb collisions, where the full Coulombic repulsion of the nuclei is reduced or screened by the effective charge of the core electrons. The role that the interatomic potential exerts on milling behavior may be best illustrated by comparing the material dependence of $Y$ (the sputtering yield) for a given set of milling parameters. TRIM was used to perform detailed calculations with full damage cascades for target materials, $Z=13-30$ milled with $25-\mathrm{keV} \mathrm{Ga}^{+}$at three incident angles $\left(0^{\circ}, 80^{\circ}\right.$, and $89^{\circ}$ as measured from the surface normal). The sputtering yield data from the aforementioned calculations are shown as 


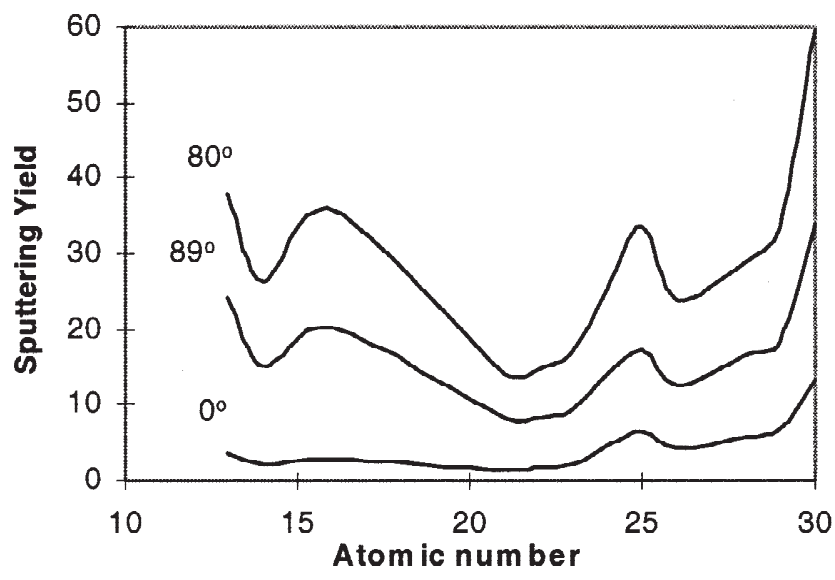

Figure 6. The plots of the computer-simulated data illustrate the material dependence of the sputtering yield for materials, $Z=$ 13-30 at three distinct incident angles. (Data modeled with TRIM'97.)

plots in Figure 6. The plots illustrate how $Y$ varies for different elements. The positions of the peaks and valleys along the abscissa indicate that the subatomic structure (i.e., the interatomic potential) of the elements exerts a controlling influence on $Y$. By comparing the three data sets it can be seen that a material with a high relative sputtering yield will mill rapidly at any incident angle; however, the magnitudes of the corresponding peaks vary with incident angle. Milling at normal incidence provides the least variation in $Y$ when different materials are compared. The contrast in $Y$ between materials is most pronounced when the beam impinges on the surface at an angle of $\sim 80^{\circ}$ from the surface normal. It follows that preferential milling between dissimilar phases would be predicted to be most salient at an incident angle of $\sim 80^{\circ}$. In addition, it is notable that although the shapes of the three curves mimic one other, they are not coincident. The relative position of each curve along the ordinate is an indication of the relative sputtering efficiency associated with that particular incident angle. It is interesting to note that $\sim 80^{\circ}$ is also the angle at which milling is most efficient in terms of sputtering yield. Thus, an $80^{\circ}$ angle of incidence may be predicted to be the most problematic for FIB electron microscopy specimen preparation, because at $80^{\circ}$, difficulties associated with redeposition would be exacerbated due to the enhanced sputtering yield. Furthermore different sputtering rates for the different elements is most pronounced at this angle.

Sputtering experiments were performed to substantiate the computer simulations described above. Four materials were sampled: (1) single crystal (100) Si, (2) single crystal (a)

(b)

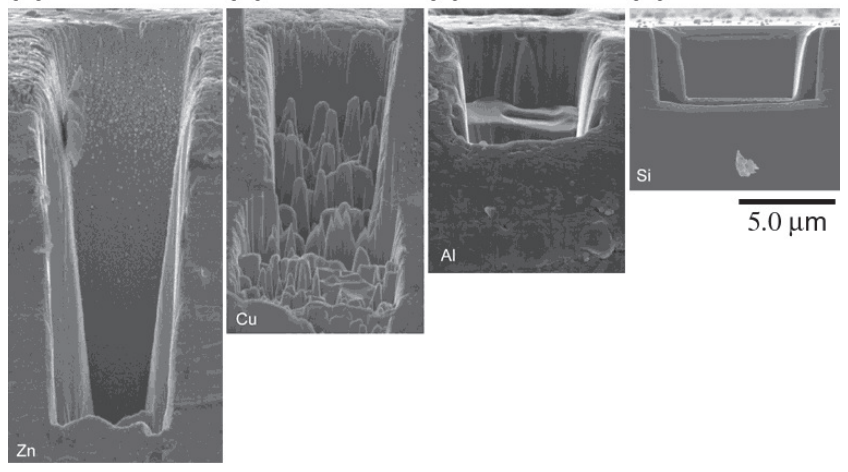

Figure 7. The cross section SEM images observed at a $90^{\circ}$ tilt show the variation between the FIB-milled trenches in $\mathrm{Zn}$ (a), $\mathrm{Cu}(\mathbf{b}), \mathrm{Al}(\mathbf{c})$, and $\mathrm{Si}(\mathbf{d})$. The milling was performed by delivering a constant $\mathrm{Ga}^{+}$ion dose to each material.

(100) $\mathrm{Cu}$, (3) polycrystalline $\mathrm{Al}$, and (4) polycrystalline $\mathrm{Zn}$. Trenches were milled in each material by using a 1000-pA beam current to deliver a constant dose of $\sim 7.5 \times 10^{12} \mathrm{Ga}^{+}$ ions to each trench at normal incidence over a nominal area of $10 \mu \mathrm{m} \times 5 \mu \mathrm{m}$. The trenches were subsequently crosssectioned to facilitate SEM analysis. Figure 7a-d shows SEM images, observed at a $90^{\circ}$ tilt, of the cross-sectioned trenches in $\mathrm{Zn}, \mathrm{Cu}, \mathrm{Al}$, and $\mathrm{Si}$, respectively. The images provide a clear example of how different materials behave uniquely under the influence of the ion beam. The relative depths of the trenches in Figure 7 yield a qualitative measure of the volume of material removed for a given ion dose. Using the inverse relationship between volume and mass density, an estimate of the number of atoms ejected per incident ion (i.e., the sputtering yield) for a given material can be calculated. It is emphasized that this experiment is not intended to be presented as a rigorous quantification of $Y$, but rather as a qualitative demonstration of the periodic behavior of $Y$ for various materials.

Figure 7a shows the trench milled in $\mathrm{Zn}$. The $\mathrm{Zn}$ trench is the deepest, which is consistent with the theoretical prediction (i.e., $Y_{\mathrm{Zn}}=12.9$ atoms $/ 25 \mathrm{keV} \mathrm{Ga}{ }^{+}$ion) that $\mathrm{Zn}$ will mill the fastest of the four materials shown. The $\mathrm{Zn}$ also shows the most severe sloping of the sidewalls. This is expected behavior based on the concepts developed to explain redeposition. The high sputtering yield of $\mathrm{Zn}$ and the large trench depth collectively provide a geometrically favorable situation for redeposition. Figure $7 \mathrm{~b}$ shows a trench milled in $\mathrm{Cu}$. When observed from this angle, the morphology of the milling-induced surface irregularities that were shown in Figure 5a-c can now be identified as pyramid or cone-like. As mentioned previously, we have observed the 
formation of such features under the action of the FIB to be pervasive in $\mathrm{Cu}$ under a wide range of milling conditions. The initial target surface quality may be an important factor in the development of asperities in $\mathrm{Cu}$. The relative trench depth of $\mathrm{Cu}$ is also in agreement with the predictions at $Y_{\mathrm{Cu}}=7.0$ atoms $/ \mathrm{Ga}^{+}$ion. Figure $7 \mathrm{c}$ reveals that the $\mathrm{Al}$ does not show significant roughening under ion bombardment at normal incidence. The trench floor and sidewalls are relatively smooth, having a minimum of discontinuities. The relative depth is in accordance with the modeled $Y_{\mathrm{Al}}=$ 3.5 atoms $/ \mathrm{Ga}^{+}$ion. Figure $7 \mathrm{~d}$ is the trench milled into Si. Of the four materials shown, the Si appears to show the least incidence of milling-induced topography. The Si trench sidewalls and bottom are relatively uniform. With the exception of the nonvertical sidewalls, the trench appears virtually free from the effects of redeposition as observed by SEM. The relative trench depth observed in Si also conforms to the predicted $Y_{\mathrm{Si}}=2.1$ atoms $/ \mathrm{Ga}^{+}$ion.

The empirical evidence presented in Figure $7 \mathrm{a}-\mathrm{d}$ concurs with the material removal rates predicted by the MC models to within $\sim 10 \%$. This is significant because it lends validity to the computer-generated models. Thus, computer generated data and plots like those shown in Figure 6 can be used with relative confidence to predict behavior of materials subjected to ion beam bombardment.

\section{Effect of total stopping power on FIB-milled surfaces}

It has been established that the total stopping power is the cumulative effect of both nuclear and electronic energy dissipation components. Stopping powers and range data are essential when investigating radiation damage of a material that has been bombarded by an energetic ion beam. Such information has direct application when assessing and predicting the extent of implant related damage such as that observed in the TEM image of the trench sidewall shown in Figure 1. TRIM was used to physically model final threedimensional spatial distributions for $25 \mathrm{keV} \mathrm{Ga}^{+}$in elements $Z=3-84$.

Direct comparison of some periodic properties of the elements with the calculated stopping data yields useful results. Figures 8 and 9 show how two physical properties, melting temperature $\left(T_{m}\right)$ and mass density $\left(\rho_{m}\right)$ of the elements compare with their corresponding stopping powers. The data used to generate the plots in Figures 8 and 9 was modeled using the PRAL algorithm available in the SRIM package (Zeigler et al., 1985). Figure 8 shows a strong positive correlation between $\rho_{m}$ and stopping power. The

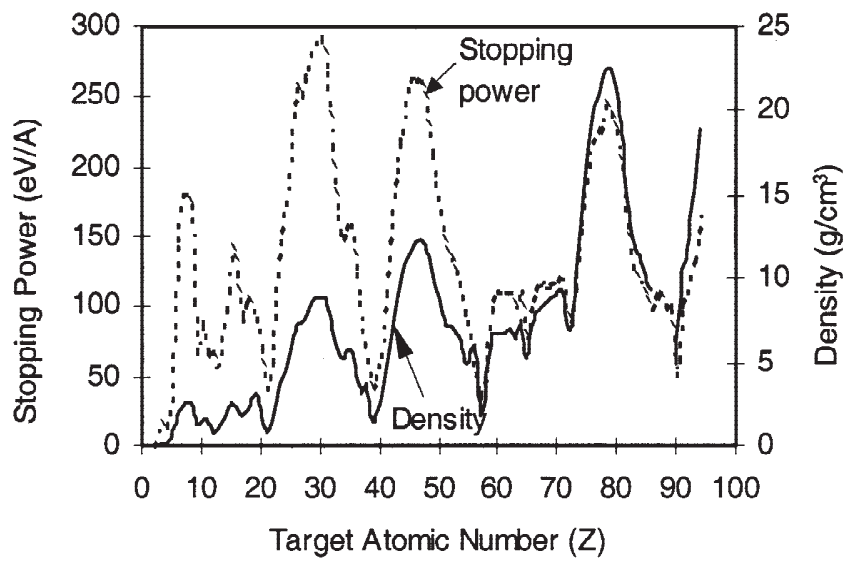

Figure 8. A plot of computer generated data superimposed on a plot of mass density shows the positive correlation between the total stopping power and the density for target elements $Z=1-92$.

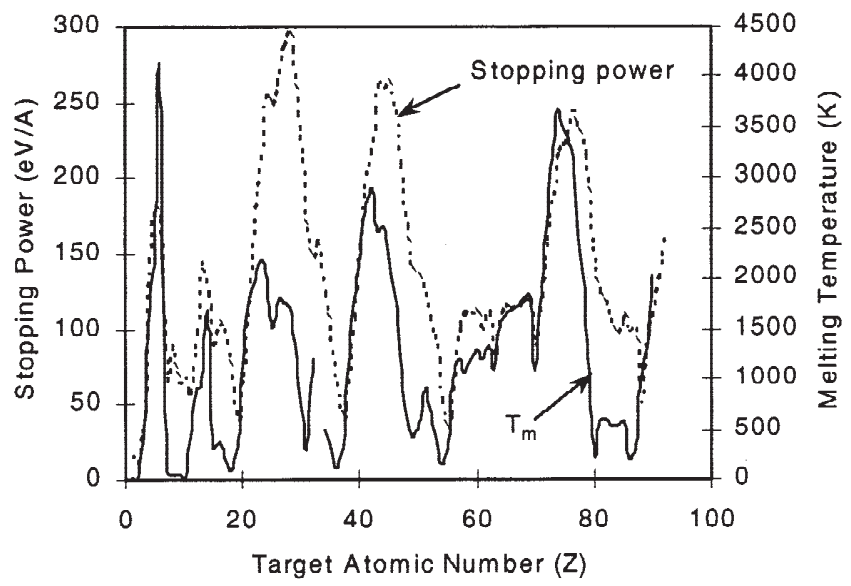

Figure 9. A plot of computer-generated data superimposed on a plot of melting temperature shows the relationship between the total stopping power and the absolute melting temperature for target elements $Z=1-92$.

position of the density and stopping power peaks are coincident for all the elements modeled. This illustrates that the stopping power for each element follows the trends associated with its particular group when moving from left to right across the periodic table. In contrast, the individual peaks exhibit a nearly random distribution in height. This indicates the absence of the influence associated with increasing mass of the elements when moving from top to bottom within a group. There is an apparent anomaly observed in the peak heights among the elements $Z=58-71$, which corresponds to the lanthanide series of elements. This may be explained by the fact that the diminished values observed 


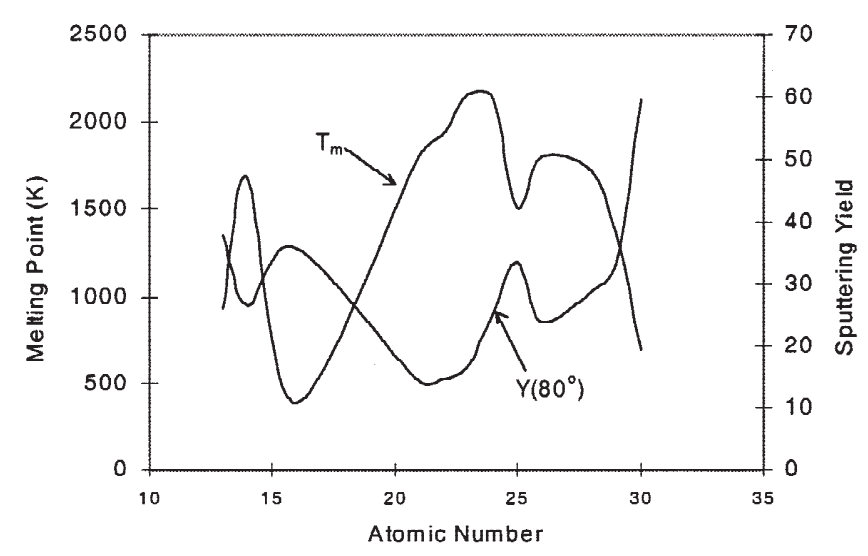

Figure 10. Computer-generated data plotted concurrently with melting temperature shows the inverse relationship between sputtering yield at an $80^{\circ}$ angle of incidence and melting temperature for elements $Z=13-30$. (Data modeled with TRIM'97.)

for the physical properties among the lanthanide group are caused by population of the $4 f$ shell in the absence of the covalent bonding contribution of the $5 d$ shell. It is the covalent character of the $d$ shells that imparts the exceptionally high strength of the interatomic bonding forces observed among the transition metals.

Figure 9 shows how stopping power compares with melting temperature. Similar to the example shown in Figure 8 , there is also a strong positive correlation between $T_{m}$ and stopping power. The position of the peaks is not matched as precisely as was observed for $\rho_{m}$; however, there is a closer match in peak magnitude between $T_{m}$ and stopping power than was observed between $\rho_{m}$ and stopping power.

Collectively, the computer modeled data plotted in Figures 8 and 9 illustrates that stopping powers and associated range distributions strongly conform to the periodic trends associated with the electronic configuration of the elements across the periodic table, and to a lesser extent to the trends associated with mass variations down a group. Thus, predictions with respect to anticipated implantation depth for a given target material may be made based on the position of the element in the periodic table.

Periodic properties of sputtering yield. The value of correlating the scattering behavior of energetic ions in a solid with some other well-established periodic trends of the elements was previously demonstrated in Figures 8 and 9. A similar comparison of sputtering behavior and melting temperature reveals that $Y$ exhibits an inverse correlation with $T_{m}$. Figure 10 shows a plot of sputtering yield data generated with TRIM for a $25-\mathrm{keV} \mathrm{Ga}^{+}$ion beam incident

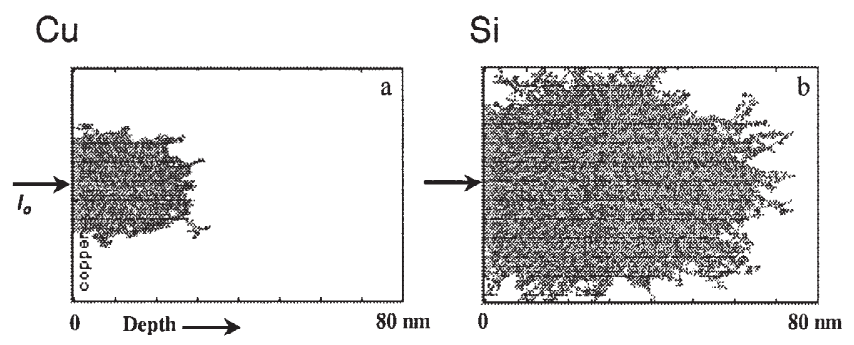

Figure 11. TRIM MC simulations of the damage cascades for $25-\mathrm{keV} \mathrm{Ga}^{+}$into $\mathrm{Si}$ (a) and $\mathrm{Cu}$ (b) at normal incidence. The simulations show the difference in the stopping powers of the two materials.

upon elements $Z=13-30$ at an angle of $80^{\circ}$ from the surface normal along with the melting temperatures for the corresponding elements. The plot indicates that the materials with the highest melting temperatures concurrently have the lowest sputtering yields. This type of relationship is intuitive, since $T_{m}$ is a direct indicator of bond strength. The more tightly bound an atom is, the more difficult it will be to eject it as a sputtered particle.

It has long been established that the periodic variation in the physical properties of the elements is dictated by the forces that bind the constituent atoms together. The evidence presented leads to the conclusion that phenomena such as $Y$ and range distributions can also be regarded as periodic properties of the elements. This allows the familiar and readily accessible periodic table to be used as a tool to predict expected milling behaviors.

Effect of collision volume on sputtering yield. The volume of the collision cascade is determined by the stopping power for a given target material. The range or depth that an incident ion penetrates into a target will be less in a material with a greater stopping power. Thus, lattice defects in such a material would be confined nearer to the surface. Figure 11a,b illustrates the influence that stopping power exerts on the respective magnitudes of the collision volumes for $\mathrm{Cu}$ and $\mathrm{Si}$.

The more compact collision volume in $\mathrm{Cu}$ may affect specimen surface characteristics in ways beyond defining the range of anticipated ion implantation damage. There may also be a quantifiable relationship between the stopping range and the redeposition-related milling artifacts observed in FIB-prepared electron microscopy specimens. When considering the dynamics of the interaction volume, collisions are not restricted to the interior of the cascade. Moving atoms also suffer elastic collisions with surface 
atoms. Sputtering occurs when such a collision results in momentum transfer normal to the surface that is sufficient in magnitude to overcome the surface binding energy of the solid. The probability of such a collision resulting in a sputtering event is enhanced when the entire cascade is proximal to the surface. As an illustrative example, the sputtering behaviors of $\mathrm{Cu}$ and $\mathrm{Si}$ are compared. Using the FEI 611 with a $25-\mathrm{keV} \mathrm{Ga}^{+}$beam, it has been experimentally observed that $\mathrm{Cu}$ sputters $\sim 3.5$ times faster than $\mathrm{Si}$. Although it has been demonstrated that $Y$ for a given target material does exhibit a strong inverse correlation with $T_{m}$, the ratio of the absolute melting temperatures of $\mathrm{Si}: \mathrm{Cu}$ is only 1.2:1. The $\sim 20 \%$ weaker bond strength of $\mathrm{Cu}$ as compared with Si does not account for the observed $~ 350 \%$ greater sputtering yield. This discrepancy suggests that the controlling mechanism for sputtering yield has a substantial physical component in addition to basic bond strength. $Y_{\mathrm{Cu}}$ may be further enhanced with respect to $Y_{\mathrm{Si}}$ because the entire volume of moving atoms in the $\mathrm{Cu}$ cascade is closer to the surface. Furthermore, this result indicates that although the periodic table may certainly be used to predict relative sputtering yields, empirical data or computer models should be referenced when absolute sputtering yields are required.

Angular dependence of sputtering yield. Substantial variations in sputtering yield can be observed as the incident angle of the ion beam is varied. By convention, the angle of incidence is measured from the surface normal. The effect of incident angle on $Y$ was investigated by performing a series of 40 TRIM calculations, in which each computation consisted of $\sim 10,000$ ions for statistical significance. The simulations were executed as detailed calculations with full damage cascades for $25-\mathrm{keV} \mathrm{Ga}^{+}$as the incident ion, and $\mathrm{Si}$, $\mathrm{Al}, \mathrm{Cu}$, and $\mathrm{Zn}$ as the targets. Sputtering yields were calculated every $10^{\circ}$ in the angular range of 0 to $80^{\circ}$, and every $2^{\circ}$ in the range of $81^{\circ}$ to $89^{\circ}$. The results are shown in Figure 12. Figure 12 concisely shows how $Y$ varies with angle of incidence for the four materials. Each material exhibits a maximum in $Y$ when milled at an incident angle of $80^{\circ} \pm$ $5^{\circ}$. Although there are only four materials shown here, analogous trends for other materials have been documented (Yamaguchi et al., 1985; Xu et al., 1992; Ishitani et al., 1994; Prenitzer et al., 1998).

When the plots for the four materials are plotted together in Figure 12, the relative position of each data set along the ordinate illustrates the material dependence of the sputtering yield. This graph shows that $\mathrm{Zn}$ sputters most rapidly of the four materials shown, and $\mathrm{Si}$ sputters the

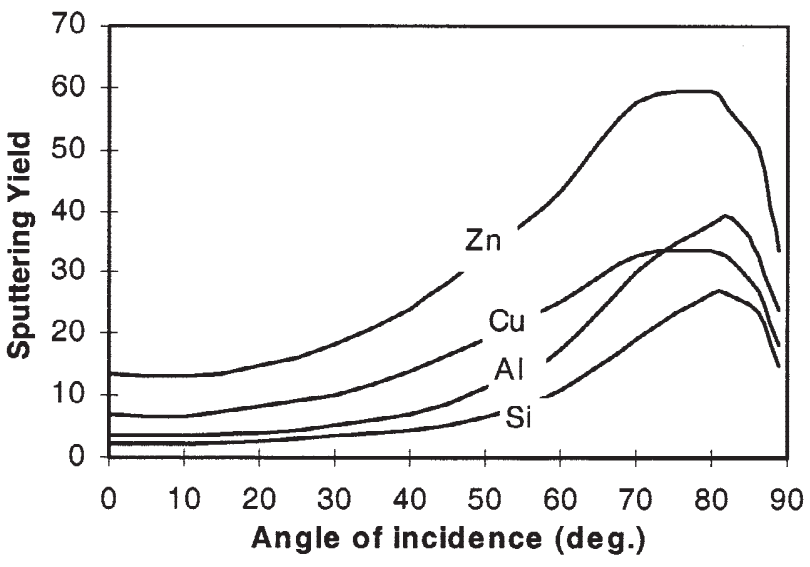

Figure 12. The plots of the computer-generated data show how the sputtering yield varies with the incident milling angle for $\mathrm{Si}$, $\mathrm{Al}, \mathrm{Cu}$, and $\mathrm{Zn}$. (Data modeled with TRIM'97.)

slowest at any incident angle; however, $\mathrm{Cu}$ sputters faster than $\mathrm{Al}$ until the curves cross over at $\sim 73^{\circ}$. The relative $Y$ for the four materials at normal incidence are in agreement with the results shown earlier in the section addressing the material dependence of $Y$.

The similarity in the shape of each curve indicates that the angle of incidence and material properties exert independent influences on $Y$ (i.e., inherent elemental properties of a target are not altered by varying the relative orientation of the incident ion beam). As a corollary, this suggests that the controlling mechanism for the variation in $Y$ with incident angle is physical rather than chemical in nature. The mechanism can be explained by once again considering the collision volume. As the angle of incidence is increased, the orientation of the collision cascade is skewed toward the target surface. At large incident angles, the sample surface makes an oblique intersection with the interaction volume, thus maximizing the surface area from which atom ejection may occur. Additionally, at large incident angles, the direction of the collision cascade is oriented in such a way as to increase the probability of backward-scattering events with the potential to cause sputtering.

Figure 13a-d shows the results of MC computer simulations for $25-\mathrm{keV} \mathrm{Ga}^{+}$into amorphous Si produced with TRIM. The plots are two-dimensional projections of the cascade volume such that a cross-sectional perspective of depth (shown on the abscissa) as a function of the lateral dimension (shown on the ordinate) is presented. Figure 13a shows the collision cascade created by $25 \mathrm{keV} \mathrm{Ga}^{+}$impinging on an amorphous Si target at normal incidence. Figure $13 \mathrm{c}$ shows the resulting cascade volume when the incident 

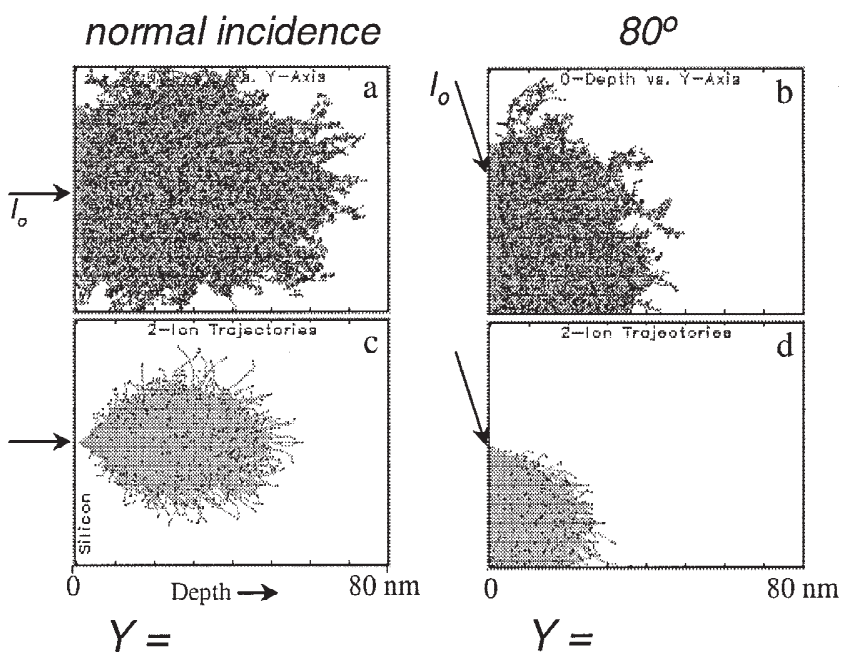

Figure 13. Monte Carlo computer simulations for $25-\mathrm{keV} \mathrm{Ga}^{+}$ into amorphous Si. a: The full damage cascade at normal incidence. b: The ion trajectories at normal incidence. c: The full damage cascade at $\theta=80^{\circ}$ from normal. $\mathbf{d}$ : The ion trajectories at $\theta=80^{\circ}$ from normal.

beam makes an angle of $80^{\circ}$ with the surface normal. By comparing Figure 13a and c, it can be seen that the area of the cascade volume adjacent to the surface is much larger when $\theta=80^{\circ}$. Accordingly, the resulting sputtering yield is predicted to be $\sim 14$ times greater at the $80^{\circ}$ incident angle than at normal incidence.

In addition to influencing sputtering yield, the milling angle affects the ion implantation range distributions and, presumably, the lattice defects that may be produced in the target. The MC simulations shown in Figure 13a-d can be used as a gauge to predict the expected depth of lattice defects resulting from energetic ion bombardment. Figure 13a,c shows the full damage cascades produced by the incident projectiles. The full damage cascade simulation corresponds to the region where point and line defects would be anticipated. Figure 13b,d shows the ion trajectories without the accompanying recoil information. The MC simulations in Figure 13b,d can be used to predict the extent of the region with the potential for $\mathrm{Ga}^{+}$ion implantation. Examination of the MC simulations indicates that the magnitude of the region that contains defects should be reduced at greater incident angles.

If the MC simulations in Figure 13a-d are compared with the cross-sectional TEM image of the FIB trench wall shown in Figure 1, correlations between the observed target damage and the collision cascade/ion range simulations can be made. It should be noted that the angle made between the incident ion beam and the wall of the FIB trench in Figure 1 was near glancing. As such, comparison with the simulations in Figure 13b,d would be expected to be the most relevant. The thickness of what is identified as the $\mathrm{Si}$ amorphous/redeposited region in Figure 1 is $\sim 14 \mathrm{~nm}$. This is in reasonable agreement with the depth at which the highest concentration of $\mathrm{Ga}^{+}$ions is predicted by the simulation in Figure 13d. The extent of what has been identified as the Si damage region in Figure 1 extends for $>200 \mathrm{~nm}$; however, the largest concentration of defects appears to be confined to within $80 \mathrm{~nm}$ of the edge of the trench wall. This distance is $\sim 50 \%$ greater than that which is predicted by the collision cascade simulation shown in Figure 13c. This discrepancy may possibly be attributed to the fact that channeling of $\mathrm{Ga}^{+}$ions in (100) Si increases the range of the incident ions (i.e., the depth of damage). The empirically observed effects attributed to channeling are not taken into account in the TRIM simulations, since the software models all targets as amorphous.

Comparison of the modeled data with empirical evidence once again indicates that the TRIM program can be used to make reasonable qualitative estimates of millinginduced damage depth as well as estimates of sputtering yield.

Optimal milling angle to reduce surface artifacts. According to the MC models, the collision cascade/ion implant depth (which leads to the production of lattice defects) is minimized at large incident angles, while sputtering yield (which leads to redeposition) is maximized at large incident angles. Redeposition and lattice defects both contribute to the creation of surface damage in electron microscopy specimens prepared by FIB methods (Rajsiri et al., 2002). Figure 14 shows the results of MC simulations for variations in sputtering yield and implant depth with incident angle for both $\mathrm{Si}$ and $\mathrm{Zn}$. Computer models such as those shown in Figure 14 can be used to illustrate the inverse relationship between implant depth and sputtering yield with respect to incident angle. Such data may assist in determining optimal milling angles to coincide with materialspecific milling behavior.

Milling-induced topography. As observed in Figures 5a-c and $7 \mathrm{~b}$, the propensity of $\mathrm{Cu}$ to mill nonuniformly illustrates the influence that material-specific properties can exert on milling-induced topography. In addition to material inherent properties, other factors such as incident milling angle, surface condition, and beam current are significant. Concepts developed in the previous sections can be used to understand the processes by which undesirable 


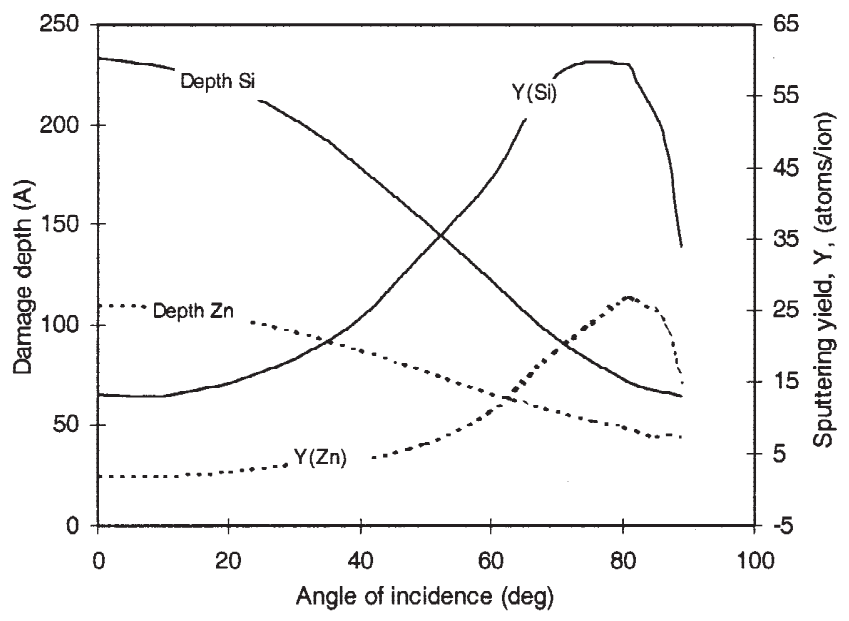

Figure 14. Plots of computer-simulated data are used to illustrate the inverse relationship between ion implant depth and sputtering yield as a function of incident angle for both Si and $\mathrm{Zn}$.

topographical features are formed. The angular dependence of sputtering yield in conjunction with the directional preference for the ejection of a sputtered particle are central to current theories concerning the formation of localized topographical features during broad ion beam bombardment (Auciello and Kelly, 1984; Barna et al., 1988, 1990; Moore and Srinivasan, 1988; Oliva, 1989; Xu et al., 1992; Kempshall et al., 2001). The experimental evidence in the literature and evidence that is presented in this work collectively suggests that similar phenomena also occur during FIB processes. The material removal rate is highly dependent on the incident angle, and the severity of redeposition is sensitive to both sputtering yield and local geometry. Thus, once an irregularity is nucleated, its growth tends to be self-perpetuating. Figure 15 schematically illustrates how milling cannot continue in a homogeneous fashion once a topographic anomaly has initiated. Work done by Barna et al. (1988) shows how once an asperity has been nucleated, each point will sputter at a different rate in accordance with the particular angle of incidence at that point. Additionally, the irregular surface area establishes conditions that are geometrical and dynamically favorable for severe redeposition to occur.

When considering FIB electron microscopy specimen preparation by the in situ lift-out technique, it is important to remember that the region of interest, which will ultimately become the TEM specimen, lies directly below the metal line and is contained in what will become a trench sidewall. At the onset of FIB electron microscopy speci-

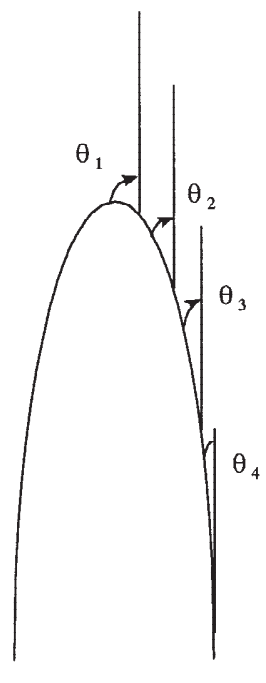

$\theta_{1} \neq \theta_{2} \neq \theta_{2} \neq \theta_{4}$

Figure 15. A schematic diagram showing how the formation of undesired topography can arise due to the localized angular variation in sputtering yield, and the preferential direction for ejection of sputtered atoms.

men preparation, the beam impinges on the target surface at normal incidence. As the trench deepens, the incident angle with respect to the trench sidewall (e.g., the region of interest) is dynamically increased to its ultimate value where the beam is nearly parallel to the specimen surface. Therefore, Figure 15 can also be viewed as a schematic representation of the range of incident angles to which a TEM specimen may be subjected during FIB milling. Although the majority of the region of interest is milled at near grazing incidence, the target is subjected to a range of incident angles that must be considered when assessing the potential to induce artifacts in a specimen prepared by FIB methods. Figure 16 is a low magnification BF TEM image of the same trench sidewall that was presented earlier in Figure 1. Figure 1 was used to illustrate how lattice defects can result from the FIB milling process. Figure 16 shows that the trench milled in $\mathrm{Si}$ is rounded at the top and that the sidewalls deviate from vertical. It was demonstrated in Figure $7 \mathrm{a}-\mathrm{d}$ that the magnitude of the slope angle will vary with material, but the $\mathrm{V}$ shape is a prevalent characteristic of high-aspect-ratio, FIB-milled features. The trench as shown in Figure 16 reemphasizes that a specimen is not milled at a single angle; therefore development of milling-induced topography and degree of amorphization can be expected to vary with position on an FIB-milled surface. 


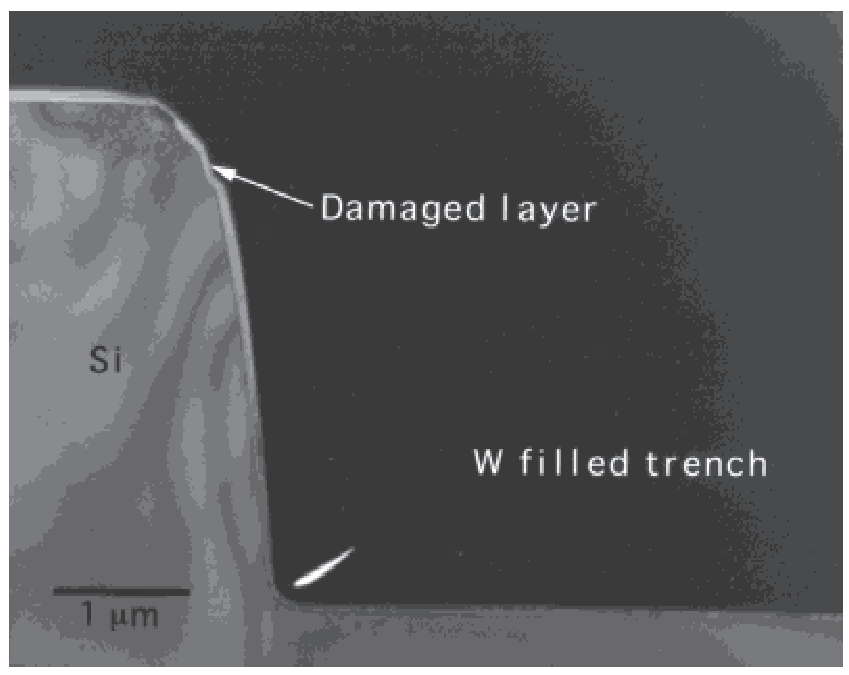

Figure 16. A cross section TEM micrograph of a trench that was milled in Si using a 1000-pA beam in an FIB. The micrograph illustrates how the observable sidewall damage varies with incident milling angle.

\section{CONCLUSIONS}

FIB electron microscopy techniques have been shown to be viable for the production of specimens from a number of materials. Although empirical evidence clearly indicates that the quality of an FIB LO specimen is sufficient to satisfy the necessary conditions for HREM imaging of $\mathrm{Si}$, it has been observed that FIB-milled features tend to exhibit some surface degradation as a direct result of the milling process. Both amorphization due to ion-target interaction and redeposition of sputtered material contribute to the observed damage. The magnitude of the surface disruption depends on inherent material properties such as beam current, incident ion energy, trench/feature geometry, raster pattern, milling angle, and the particular ion column being used. Problems associated with redeposition (e.g., exaggerated sidewall sloping or formation of undesired topography) are enhanced by factors that increase the sputtering rate. Redeposition related effects can be anticipated when milling highaspect-ratio features and/or materials that sputter very rapidly, but can be partially counteracted by milling at the lowest beam current tolerable within the time constraints. Stopping powers and range data are significant when considering potential microstructural modification due to ion implantation and vacancy production during FIB milling of electron microscopy specimens. Ion range is observed to decrease as the incident angle is increased; however, materi- als generally exhibit a maximum in sputtering yield when milled at an incident angle of $80^{\circ} \pm 5^{\circ}$. Therefore, artifacts associated with redeposition would tend to be exacerbated at incident angles of $\sim 80^{\circ}$ due to the enhanced sputtering rate, while artifacts resulting from ion implantation would tend to be attenuated. By considering both contributions, the incident milling angle may be optimized for a given ion-target combination so as to minimize the extent of FIB-milling-induced artifacts and improve the specimen surface quality.

It has been shown that different materials behave uniquely under the influence of the ion beam. The strong material dependence of scattering behavior observed in ion-atom collisions corresponds to the periodic trends observed for other physical phenomena in condensed phase materials (i.e., melting temperature, density, hardness, elastic modulus, and thermal expansion behavior). The evidence presented leads to the conclusion that phenomena such as $Y$ and range distributions can also be regarded as periodic properties of the elements. Thus, milling-related artifacts may be minimized by using the periodic table to predict the milling behavior of specific materials of interest and then selecting the FIB parameters accordingly.

\section{RefERENCES}

Adesida, I. \& Karapiperis, L. (1982). Monte Carlo simulation of ion beam penetration in solids. Radiation Effects 61, 223-233.

Anderson, R.M. \& Walck, S.D. (Eds.) (1997). Proceedings of the Materials Research Society Symposium: Specimen Preparation for Transmission Electron Microscopy of Materials IV. Warrendale, PA: Materials Research Society.

Auciello, O. \& Kelly, R., eds. (1984). Ion Bombardment Modification of Surfaces. Amsterdam: Elsevier.

Barna, A., Barna, P.B. \& Zalar, A. (1988). Ion beam induced roughness and its effects in AES depth profiling of multilayer $\mathrm{Ni} / \mathrm{Cr}$ thin films. Surf Interface Anal 12, 144-150.

Barna, A., Barna, P.B. \& Zalar, A. (1990). Analysis of the development of large area surface topography during ion etching. Vacuum 40, 115-120.

Basile, D.P., Boylan, R., Baker, B., Hayes, K. \& Soza, D. (1992). FIBXTEM-Focused ion beam milling for TEM sample preparation. In Proceedings of the Materials Research Society: Specimen Preparation for Transmission Electron Microscopy of Materials III, Anderson, R., Tracy, B. \& Bravman, J. (Eds.), Vol. 254, pp. 23-41. Pittsburgh, PA: Materials Research Society.

Bender, H., Van Marcke, P., Drijbooms, C. \& Roussel, P. (1998). Focused ion beam preparation for cross-sectional trans- 
mission electron microscopy investigation of the top surface of unpassivated or partially processed ULSI devices. In Proceedings of the International Conference on Characterization and Metrology of ULSI Technology, Seiler, D.G., Diebold, A.C., Bullis, W.M., Shaffner, T.J., McDonald, R. \& Walters, E.J. (Eds.), Vol. 449, pp. 863-867. Woodbury, NY: American Institute of Physics.

Biersack, J.P. \& Haggmark, L.G. (1980). A Monte Carlo program for the transport of energetic ions in amorphous targets. Nucl Instrum Methods 174, 257-269.

Brimhall, J.L., Kissinger, H.E. \& Charlot, L.A. (1983). Amorphous phase formation in irradiated intermetallic compounds. Radiation Effects 77, 45.

Campbell, A.N. \& Soden, J.M. (1998). Direct imaging of device characterization in a focused ion beam system. Microsc Microanal 4 (Suppl. 2), 652-653.

Chabala, J.M., Levi-Setti, R. \& Wang, Y.L. (1988). Imaging microanalysis of surfaces with a focused gallium probe. $J$ Vac Sci Technol B 6, 910-914.

Crandle, T.L., Grabowski, W.B. \& Kump, M.R. (1989). Analysis of ion implant processes through Monte Carlo based simulation. In NA-SECODE VI Short Course on Software Tools for Process, Device and Circuit Modeling, pp. 43-45.

FEI Focused Ion Beam Application Note. (1993). High aspect ratio hole drilling using FIB enhanced etch process. Hillsboro, OR: FEI Company.

Garrison, B.J., Blumenthal, R., Caffey, K., Furman, E. \& Winograd, N. (1994). Angular distribution of $\mathrm{Ga}^{+}$ions desorbed by $3 \mathrm{keV}$ ion bombardment of GaAs $\{001\}(2 \times 4)$. In Proceedings SIMS VIII, Benninghoven, A., Janssen, K.T.F., Tumpner, J. \& Werner, H.W. (Eds.), pp. 65-66. Chichester, UK: Wiley.

Giannuzzi, L.A., Drown, J.L., Brown, S.R., Irwin, R.B. \& Stevie, F.A. (1997). Focused ion beam milling and micromanipulation lift-out for site specific cross-section TEM specimen preparation. In Proceedings of the Materials Research Society Symposium: Workshop on Specimen Preparation for TEM of Materials IV, Anderson, R. \& Walck, S. (Eds.), Vol. 480, pp. 19-27. Pittsburgh, PA: Materials Research Society.

Giannuzzi, L.A., Drown, J.L., Brown, S.R., Irwin, R.B. \& Stevie, F.A. (1998). Applications of the FIB lift-out technique for TEM specimen preparation. Microsc Res Technique 41, 285-290.

Giannuzzi, L.A., Brown, S.R., Prenitzer, B.I., DrownMacDonald, J.L., Shofner, T.L., Irwin, R.B. \& Stevie, F.A. (1999a). Advances in the FIB lift-out technique for TEM specimen preparation: HREM lattice imaging. In Microstructural Science: Proceedings of the Annual Technical Meeting of the International Metallographical Society, Vol. 26, pp. 249-253. Pittsburgh, PA: Materials Research Society.

Giannuzzi, L.A. \& Lewinsohn, C.A. (1999c). Interphase oxidation in SIC/SIC composites at varying partial pressures of oxygen. In Proceedings of the Annual Conference on Composites, Advanced Ceramics, Materials, and Structures: B, Ceramic Engi- neering and Science, Ustundag, E. \& Fischman, G. (Eds.), Vol. 20, pp. 115-122. Westerville, OH: The American Ceramic Society. Giannuzzi, L.A. \& Lewinsohn, C.A. (2000). Interphase oxidation in SIC/SIC composites. In Proceedings of the Annual Conference on Composites, Advanced Ceramics, Materials, and Structures: A, Ceramic Engineering and Science, Jansen, T. \& Ustundag, E. (Eds.), Vol. 21, pp. 469-477. Westerville, OH: The American Ceramic Society.

Giannuzzi, L.A., Prenitzer, B.I., Drown-MacDonald, J.L., Shofner, T.L., Brown, S.R., Irwin, R.B. \& Stevie, F.A. (1999b). Electron microscopy sample preparation for the biological and physical sciences using focused ion beams. J Process Analyt Chem 4, 162-167.

Gibbons, J.F., Johnson, W.S. \& Mylroie, S.W. (1975). Projected Range Statistics: Semiconductors and Related Materials. Stroudsburg, PA: Dowden, Hutchinson, and Ross, Inc.

Goodhew, P.J. (1985). Thin foil preparation for electron microscopy. In Practical Methods in Electron Microscopy, Vol. II, Glauert, A.M. (Ed.), Amsterdam: Elsevier.

Guinan, M.W. \& Kinney, J.H. (1982). Molecular dynamic calculations of energetic displacement cascades. J Nucl Mater 104(1-3), $1319-1324$.

Herlinger, L.R., Chevacharoenkul, S. \& Erwin, D.C. (1996). TEM sample preparation using a focused ion beam and a probe manipulator. In ISTFA '96, Proceedings of the 22nd International Symposium for Testing Failure Analysis, pp. 199-205. Materials Park, OH: ASM International.

Huffman, K.V., Hoener, C.F. \& Shaver, B. (1994). FIB sample preparation to reduce charging for AUGER analysis. In ISTFA '94, Proceedings of the 20th International Symposium for Testing and Failure Analysis, pp. 365-375. Materials Park, OH: ASM International.

Hull, R. (1998). Direct transmission electron microscope observations of doping variations in InP based semiconductor laser diodes. Microsc Microanal 4 (Suppl. 2), 648-649.

Hull, R., Bahnck, D., Stevie, F.A., Koszi, L.A. \& Chu, S.N.G. (1993). Microscopic studies of semiconductor lasers utilizing a combination of transmission electron microscopy, electroluminescence imaging, and focused ion beam sputtering. Appl Phys Lett 62, 3408-3410.

Hull, R., Stevie, F.A. \& BAhnck, D. (1995). Observation of strong contrast variation from doping variations in transmission electron microscopy of InP-based semiconductor laser diodes. Appl Phys Lett 66, 341-343.

Ishitani, T., Hirose, H. \& Tsuboi, H. (1995). Focused-ionbeam digging of biological specimens. J Electron Microsc 44, $110-114$.

Ishitani, T., Tsuboi, H., Yaguchi, T. \& Koike, H. (1994). Transmission electron microscope sample preparation using a focused ion beam. J Electron Microsc 43, 322-326.

Kamino, T., Yaguchi, T., Matsumoto, H., Томita, M. \& Koike, H. (1998). A new method for pinpoint failure analysis using 
FIB combined analytical TEM. Microsc Microanal 4 (Suppl. 2), 654-655.

Kempshall, B.W., Prenitzer, B.I., Giannuzzi, L.A., DA, S. \& Stevie, F.A. (2002). A comparative evaluation of FIB CVD processes. J Vac Sci Technol B 1, 286-290.

Kempshall, B.W., Schwarz, S.M., Prenitzer, B.I., Giannuzzi, L.A., Irwin, R.B. \& Stevie, F.A. (2001). Ion channeling effects on the focused ion beam milling of Cu. J Vac Sci Technol B 19, 749-754.

Kirk, E.C., Williams, D.A. \& Ahmed, H. (1989). Cross-sectional transmission electron microscopy of precisely selected regions from semiconductor devices. Inst Phys Conf Series 100, 501.

Kitano, Y., Fujukawa, Y., Kamino, T., Yaguchi, T. \& Saka, H. (1995). TEM observation of micrometer-sized Ni powder particles thinned by FIB cutting technique. J Electron Microsc 44, $410-413$.

LAngford, R.M. \& Petford-Long, A.K. (2001). Broad ion beam milling of focused ion beam prepared transmission electron microscopy cross sections for high resolution electron microscopy. J Vac Sci Technol A 19, 982-985.

Lindhard, J. (1953). Mat Fys Medd Dan Vid Selsk 28.

Lindhard, J., Scharff, M. \& Schiott, H.E. (1954). Range concepts on heavy ion ranges: Notes on atomic collisions II. Mat Fys Medd Dan Vid Selsk 33, 15.

Lomness, L.K., Giannuzzi, L.A. \& Hampton, M.D. (2000). Site specific TEM analysis of micrometer-sized particles with the FIB lift-out technique. Microsc Microanal 6 (Suppl 2), 518-519.

Lomness, L.K., GiannUZZI, L.A. \& HAMPTON, M.D. (2001a). TEM characterization of sub-micrometer particles using the FIB lift-out technique Microsc Microanal 7, 418-423.

Lomness, L.K., Kempshall, B.K., Giannuzzi, L.A. \& Watson, M.B. (2001b). TEM of sub-micrometer particles using the FIB lift-out technique. Microsc Microanal 7 (Suppl. 2), 950-951.

Mackenzie, J.M., Griffis, D.P. \& Russell, P.E. (1994). Nanosurgery of biological specimens using chemically enhanced focused ion beam etching. In Proceedings of the Microscopy Society of America 52nd Annual Meeting, Baily, G.W. \& Garratt-Reed, A.J. (Eds.), pp. 366-367. San Francisco, CA: San Francisco Press.

Mackenzie, J.M., Woodward, T.H., Dieter, P. \& Russell, P.E. (1993). Nanosurgery of biological specimens using a focused ion beam. In Proceedings of the Microscopy Society of America 51st Annual Meeting, pp. 246-247. San Francisco, CA: San Francisco Press.

Moore, J.S. \& Srinivasan, G.R. (1988). Monte Carlo simulation of ion implantation in crystalline silicon using Marlowe. $J$ Electrochem Soc: Solid-State Sci Technol 135, 2034-2038.

Nakajima, K. \& Sudo, S. (1993). Layer structure evaluation of multilayer X-ray mirror by combination of focused ion beam etching and transmission electron microscopy. J Vac Sci Technol B 11, 2127-2130.

Nastasi, M., Mayer, J.W. \& Hirvonen, J.K. (1996a). Phase trans- formations. Ion-Solid Interactions: Fundamentals and Applications, pp. 351-359. New York: Cambridge University Press.

Nastasi, M., Mayer, J.W. \& Hirvonen, J.K. (1996b). Ion stopping. Ion-Solid Interactions: Fundamentals and Applications, pp. 88-112. New York: Cambridge University Press.

Nastasi, M., Mayer, J.W. \& Hirvonen, J.K. (1996c). Ion range and range distribution. Ion-Solid Interactions: Fundamentals and Applications, pp. 115-138. New York: Cambridge University Press.

Oliva, A. (1989). Historical overview on the fundamentals of sputtering. In Materials Modification by High-Fluence Ion Beams, Kelly, R. \& Fernanda da Silva, M. (Eds.), pp. 1-11. Netherlands: Kluwer Academic Publishers.

Overwijk, M.H.F., van den Heuvel, F.C. \& Bulle-Lieuwma, C.W.T. (1993). Novel scheme for the preparation of transmission electron microscopy specimens with a focused ion beam. J Vac Sci Technol B 11, 2021-2024.

Phaneuf, M.W., Li, J. \& Malis, T. (1998). High resolution FIB as a general materials science tool. Microsc Microanal 4 (Suppl. 2), 492-493.

Phaneuf, M.W., Rowlands, N., Carpenter, G.J.C. \& Sundaram, G. (1997). Focused ion beam sample preparation of nonsemiconductor materials. In Proceedings of the Materials Research Society, Anderson, R.M. \& Walck, S.D. (Eds.). Vol. 480, p. 39. Pittsburgh, PA: Materials Research Society.

Prenitzer, B.I. (1999). Investigation of variables affecting focused ion beam milling as applied to specimen preparation for electron microscopy: A correlation between Monte Carlo based simulation and empirical observation. Ph.D. Dissertation, University of Central Florida.

Prenitzer, B.I., Giannuzzi, L.A., Newman, K., Brown, S.R., Irwin, R.B., Shofner, T.L. \& Stevie, F.A. (1998). Transmission electron microscope specimen preparation of $\mathrm{Zn}$ powders using the focused ion beam lift-out technique. Met Trans A 29, 2399-2405.

Rajsiri, S., Kempshall, B.W., Schwarz, S.M. \& Giannuzzi, L.A. (2002). FIB damage in Si: Amorphization or redeposition? Microsc Microanal 8 (Suppl. 2), 50-51.

Readinger, E.D., Wolter, S.D., Waltemyer, D.L., Delucca, J.M., Mohney, S.E., Prenitzer, B.I., Giannuzzi, L.A. \& Molnar, R.J. (1999). Wet thermal oxidation of GaN. J Electronic Mater 28, 257-260.

Robinson, M.T. \& Torrens, I.M. (1974). Computer simulation of atomic-displacement cascades in solids in the binary-collision approximation. Phys Review B 9, 5008.

Rosencrance, S.W., Burnham, J.S., Sanders, D.E., Garrison, B.J. \& Winograd, N. (1995). Mechanistic study of atomic desorption resulting from the $\mathrm{keV}$-ion bombardment of FCC \{001\} single-crystal metals. Phys Review B 8, 6006-6014.

SAnborn, C.E. \& Myers, S. (1992). Precision TEM sample preparation using focused ion beam marking strategies. In Proceedings of the Materials Research Society: Specimen Preparation for 
Transmission Electron Microscopy of Materials III, Anderson, R., Tracy, B. \& Bravman, J. (Eds.), Vol. 254, pp. 239-248. Pittsburgh, PA: Materials Research Society.

Sanders, D.E., Prasad, K.B.S., Burnham, J.S. \& Garrison, B.J. (1994). Mechanistic analysis from molecular dynamics simulations: keV-particle-induced desorption from Si $\{001\}$. Phys Rev B 8, 5358-5369.

Sheng, T.T., Goh, G.P., Tung, C.H. \& Wang, L.F. (1997). Precision transmission electron microscopy sample preparation using a focused ion beam by extraction method. J Vac Sci Technol B 15, 610-613.

Stevie, F.A., Downey, S.W., Brown, S., Shofner, T., Decker, M., Dingle, T. \& Christman, L. (1998b). Microscale elemental imaging of semiconductor materials using focused ion beam SIMS. Microsc Microanal 4 (Suppl. 2), 650-651.

Stevie, F.A., Irwin, R.B., Shofner, T.L., Brown, S.R., Drown, J.L. \& Giannuzzi, L.A. (1998a). Plan View Sample Preparation Using the Focused Ion Beam Lift-Out Technique. In Proceedings of the 1998 International Conference on Characterization and Metrology of ULSI Technology, Seiler, D.G., Diebold, A.C., Bullis, W.M., Shaffner, T.J., McDonald, R. \& Walters, E.J. (Eds.). Vol. 449, pp. 868-871. Woodbury, NY: American Institute of Physics.

Stevie, F.A., Shane, T.C., Kahora, P.M., Hull, R., Bahnck, D., Kanna, V.C. \& David, E. (1995). Applications of focused ion beams in microelectronics production, design and development. Surf Interface Anal 23, 61-68.

Stevie, F.A., Vartuli, C.B., Mills, R.H., Irwin, R.B., Shofner, T.L. \& Giannuzzi, L.A. (1999). The FIB lift-out specimen preparation technique for TEM analyses and beyond: SEM, AUGER, STEM, and SIMS applications. Microsc Microanal 5 (Suppl. 2), 888-889.

Stevie, F.A., Vartuli, C.B., Giannuzzi, L.A., Shofner, T.L., Brown, S.R., Rossie, B., Hillion, F., Mills, R.H., Antonell, M., Irwin, R.B. \& Purcell, B.M. (2001). Application of focused ion beam lift-out specimen preparation to TEM, SEM, STEM, AES, and SIMS Analysis. Surf Interface Anal 31, 345-351.

Susnitsky, D.W. \& Johnson, K.D. (1998). Focused ion beam damage formed using TEM sample preparation of silicon. Microsc Microanal 4 (Suppl. 2), 656-657.

Szot, J., Hornsey, R., Ohnishi, T. \& Minagawa, S. (1992). Focused ion beam micromachining for transmission electron microscopy specimen preparation of semiconductor laser diodes. Vac Sci Technol B 10, 575-579.

Tanaka, M., Furuya, K. \& Saito, T. (1997). Microstructural observation of focused ion beam modification of $\mathrm{Ni}$ silicide/Si thin films. In Proceedings of the Materials Research Society: Microstructure Evolution During Irradiation, Robertson, I.M., Was, G.S., Hobbs, L.W. \& De La Rubia, T.D. (Eds.). Vol. 439, pp. 227-232. Pittsburgh, PA: Materials Research Society.

Tartuani, M., Takai, Y., Shimizu, R., Uda, K. \& Takahashi, H.
(1993). Development of a focused ion beam apparatus for preparing cross-sectional electron microscope specimens. Tech Rep Osaka Univ 43, 167-173.

Urbanik, C.A., Prenitzer, B.I., Giannuzzi, L.A., Brown, S.R., Shofner, T.L., Rossie, B., Irwin, R.B. \& Stevie, F.A. (1999). Characterization of FIB damage in silicon. Microsc Microanal 5 (Suppl. 2), 740-741.

Vartuli, C.B., Stevie, F.A., Bindell, J.B., Shofner, T.L. \& PurCELL, B.M. (1999). Enhancement of SEM/EDS analysis using FIB sample preparation. Microsc Microanal 5 (Suppl. 2), 896-897. Walker, J.F. (1993). Focused Ion Beam Applications Using Enhanced Etch. Hillsboro, OR: FEI Company.

Williams, D.B. \& Carter, C.B. (1996). Transmission Electron Microscopy. New York: Plenum Press.

Xu, X., Della Ratta, A.D., Sosonkina, J. \& Mengailis, J. (1992). Focused ion beam induced deposition and ion milling as a function of angle of ion incidence. J Vac Sci Technol B 10, 2675-2680.

Yamaguchi, A. \& Shibata, M. (1993). Transmission electron microscopy specimen preparation technique using focused ion beam fabrication: Application to GaAs-semiconductor field effect transistors. J Vac Sci Technol B 11, 2016-2020.

Yamaguchi, H., Shimase, A., Haraaichi, S. \& Miyauchi, T. (1985). Characteristics of silicon removal by fine gallium ion beam. J Vac Sci Technol B 3, 71-74.

YAter, J.A. \& Thompson, M.O. (1992). Preparation of transmission electron microscopy cross sections using nanofabrication techniques. J Vac Sci Technol B 10, 183-186.

Young, R.J., Carleson, P.D., Ca, X. \& Walker, J.F. (1998). High yield and high throughput TEM sample preparation using focused ion beams. In ISTFA '98, Proceedings of the 24th International Symposium for Testing and Failure Analysis, pp. 329336. Materials Park, OH: ASM International.

Young, R.J., Cleaver, J.R.A. \& Amed, H. (1993b). Characteristics of gas-assisted focused ion beam etching. J Vac Sci Technol B 11, 234-241.

Young, R.J., Dingle, T., Robinson, K. \& Pugh, P.J.A. (1993a). An application of scanned focused ion beam milling to studies on the internal morphology of small arthropods. J Microsc 172, 81-88.

Young, R.J., Kirk, E.C., Williams, D.A. \& Ahmed, H. (1990). Fabrication of planar and cross-sectional TEM specimens using a focused ion beam. In Proceedings of the Materials Research Society: Specimen Preparation for Transmission Electron Microscopy of Materials II, Anderson, R. (Ed.). Vol. 199, pp. 205-216. Pittsburgh, PA: Materials Research Society.

Zeigler, J.F., Biersack, J.P. \& Littmark, U. (1985). The Stopping Range of Ions in Solids. New York: Pergamon Press.

Zhou, D.L.R. \& Zanoya, R. (1999). Cross-sectional transmission electron microscopy sample preparation using focused ion beam machine and wedge technique. Microsc Microanal 5 (Suppl. 2), 894-895. 